\title{
HACIA EL ESTABLECIMIENTO DEL PERFIL DEL BIBLIOTECÓLOGO A NIVEL IBEROAMÉRICA
}

COORDINADORA

Lina Escalona Ríos

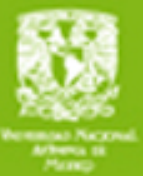


La presente obra está bajo una licencia de:

http://creativecommons.org/licenses/by-ncsa/3.0/deed.es MX

\section{(c) cointive}

Eres libre de:

(15)

copiar, distribuir y comunicar públicamente la obra

(D) hacer obras derivadas

Bajo las condiciones siguientes:

Atribución - Debes reconocer la autoría de la obra en los términos

especificados por el propio autor o licenciante.

No comercial - No puedes utilizar esta obra para fines comerciales.

Licenciamiento Reciproco - Si alteras, transformas o creas una obra a

partir de esta obra, solo podrás distribuir la obra resultante bajo una licencia igual a ésta.

Esto es un resumen fácilmente legible del: texto legal (de la licencia completa)

\section{En los casos que sea usada la presente obra, deben respetarse los términos especificados en esta licencia.}
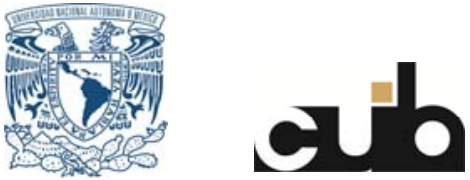
Hacia el establecimiento del perfil del bibliotecólogo a nivel

Iberoamérica 
COLECCIÓN

Cuadernos de Investigación 8

Centro Universitario de Investigaciones Bibliotecológicas 


\title{
Hacia el establecimiento del perfil del bibliotecólogo a nivel Iberoamérica
}

\author{
Coordinadora \\ Lina Escalona Ríos \\ Participantes \\ Karla Rodríguez Salas \\ Juan Carlos Marcos Recio \\ Alice Miranda Arguedas
}

Universidad Nacional Autónoma de México 2008 
Z668

A5H34 Hacia el establecimiento del perfil del bibliotecólogo a nivel Iberoamérica / coordinadora, Lina Escalona Ríos ; participantes, Karla Rodríguez Salas, Juan Carlos Marcos Recio, Alice Miranda Arguedas - México : UNAM, Centro Universitario de Investigaciones Bibliotecológicas, 2008.

xv, 71 p. - (Cuadernos de Investigación ; 8)

ISBN: 978-607-02-0770-9

El presente documento es el resultado del segundo foro de discusión, del Seminario Permanente de Educación Bibliotecológica. 1. Bibliotecarios - Perfil Profesional - Iberoamérica 2. Documentalistas 3. Diseño de Planes de Estudio I. Escalona Ríos, Lina, coordinadora II. Rodríguez Salas, Karla III. Marcos Recio, Juan Carlos IV. Miranda Arguedas, Alice. V. ser.

\section{Diseño de portada: Mario Ocampo Chávez}

Primera Edición, 2008

DR (C) UNIVERSIDAD NACIONAL AUTÓNOMA DE MÉXICO

Ciudad Universitaria, 04510, México, D.F.

Impreso y hecho en México

ISBN: 978-607-02-0770-9 


\section{Contenido}

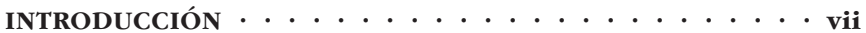

EL PROFESIONAL EN BIBLIOTECOLOGÍA Y DOCUMENTACIÓN: HABILIDADES Y COMPETENCIAS

Karla Rodríguez Salas . . . . . . . . . . . . . . . . 1

CONOCIMIENTO TECNOLÓGICO PARA EL DESARROLLO DE LA ACTIVIDAD PROFESIONAL EN BIBLIOTECOLOGÍA Y DOCUMENTACIÓN

Juan Carlos Marcos Recio . . . . . . . . . . . . . . . 33

EL PERFIL DEL GRADUADO EN BIBLIOTECOLOGÍA

Alice Miranda Arguedas . . . . . . . . . . . . . . . . . . . . 55

DISCUSIón $\ldots \ldots \ldots \ldots \ldots$ 


\title{
Introducción
}

\begin{abstract}
G sta segunda publicación del Seminario Virtual sobre Educación Bibliotecológica es producto de la discusión sobre este tema en su Foro Electrónico. Para llevar a cabo la discusión se tomaron como punto de partida los documentos base elaborados por Karla Rodríguez Salas (Costa Rica), Juan Carlos Marcos Recio (España) y Alice Miranda Arguedas (Costa Rica), los que se incluyen en la presente publicación. Asimismo, se tomaron en consideración dos ponencias elaboradas y presentadas en diferentes eventos académicos por Johann Pirela Morillo "Perfil del profesional de la información con base en competencias integradas en el contexto de un currículo cooperativo y reedificado" y Javier Tarango "Los profesionales de la información ante las nuevas necesidades de aprendizaje: el papel de la universidad y sus alcances". Todos ellos dieron la pauta para la discusión llevada en el Foro Electrónico cuyos principales aspectos abordados también se
\end{abstract}


Hacia el establecimiento del perfil del bibliotecólogo a nivel...

incluyen, finalizando con una serie de conclusiones y recomendaciones sobre el tema.

La discusión se llevó a cabo durante una semana en el Foro Electrónico, de este Seminario, contando con la participación en línea de los siguientes integrantes: Magdaleno Azotla Álvarez (Ciudad de México), Brenda Cabral Vargas (Ciudad de México), Rosa Elba Chacón Escobar (Chiapas, México), Lina Escalona Ríos (Ciudad de México), Elba Fernández Cruz (Ciudad de México), Juan Carlos Marcos Recio (Madrid, España), Alice Miranda Arguedas (San José, Costa Rica), Karla Rodríguez Salas (San José, Costa Rica), Javier Tarango (Chihuahua, México), María Elvia Vázquez Velásquez (Ciudad de México).

Indudablemente, este es un tema que requiere de una amplia discusión, puesto que la educación bibliotecológica en la región iberoamericana posee una gran diversidad de características, las que han sido abordadas por diversos autores, entre las que se pueden mencionar: la diversidad de nombres para los títulos profesionales que se otorgan, los distintos objetivos de los planes de estudio, las diversas nomenclaturas usadas para las asignaturas que los integran, así como los objetivos tan diversos que persigue cada carrera ofertada, aun cuando todas tienen el mismo campo de ejercicio profesional: la organización y administración de la información. 
En una sociedad en la que la información se ha convertido en el eje de la producción, de la economía y del desarrollo social, la divergencia de corrientes y objetivos educativos para la única profesión que tiene como base la información en todos sus aspectos organizativos y administrativos para satisfacer los requerimientos de información de la sociedad, es poco conveniente, ya que esa divergencia puede hacer irreconocible a esa profesión, motivando que otros profesionales asuman tareas para las que no han sido formados. De aquí la importancia de trabajar en un perfil profesional que cubra las vertientes internacionales y forme a profesionales competitivos capaces de desempeñarse en cualquier país que se les requiera.

Pero, ¿’por qué iniciar con el perfil profesional? ¿cuál es su importancia y características para pensar en este elemento como la base para homologar contenidos y llegar a un solo profesional iberoamericano?

Dentro de las etapas de diseño curricular se encuentra la definición de perfiles, tanto de ingreso como de egreso, así como la de profesional, perfiles que de acuerdo con el modelo educativo elegido son la base del diseño curricular.

Definiendo este tipo de perfiles, el de ingreso es el conjunto de conocimientos, habilidades y aptitudes que tiene el estudiante al ingresar a un determi- 
Hacia el establecimiento del perfil del bibliotecólogo a nivel...

nado nivel de estudios; mientras que el de egreso señala los conocimientos, habilidades y aptitudes que se esperan desarrollar a lo largo de la trayectoria académica del estudiante y que implican que éste logre un título universitario.

El perfil profesional conjuga los conocimientos y habilidades que permiten resolver los problemas que presenta la práctica profesional. Sin embargo, es necesario establecer la clara vinculación que existe entre el perfil de egreso o académico y el perfil profesional ya que las universidades "como productoras de profesionales que se integrarán a los distintos procesos de trabajo, [tienen como] responsabilidad que sus egresados se desempeñen eficazmente en la práctica profesional. Esta formación profesional está determinada por los requerimientos del mercado laboral, requerimientos que se detectan a través del análisis ocupacional y se expresan en el perfil profesional" (Allende).

El análisis ocupacional se relaciona con la optimización de la educación, específicamente la educación superior que forma profesionales que habrán de insertarse en un mercado, y sólo a través de dicho análisis pueden determinarse las características específicas del mercado e incorporarlas en los planes de estudio de forma efectiva.

Así, el perfil profesional debiese ser la base académica y profesional que permita la elaboración del 
plan de estudios para que cada elemento del perfil se convierta en una meta a conseguir a través de las asignaturas determinadas. Se prepararía así al profesional para ejercer con éxito y pertinencia su profesión.

Pero el perfil profesional va más allá de la realidad profesional y disciplinaria actual, también debe visualizar las tendencias disciplinarias y los mercados emergentes que a mediano y largo plazo se puedan ya contemplar. En este sentido el perfil es también "ideal" porque se basa en las exigencias profesionales actuales y futuras. De esta forma, el perfil profesional es importante porque:

- Sistematiza el conjunto de conocimientos, habilidades y actitudes para el ejercicio profesional y, - Delimita las características formativas del alumno.

La metodología para elaborar el perfil tiene que partir de estudios previos que prevean un contexto firme en el cual desarrollar cada elemento que conforma el perfil. Entre estos estudios, es de suma importancia el de seguimiento de egresados que dé cuenta de la actualización de los planes de estudio y de la evaluación de su impacto social; el análisis del plan vigente y los estudios de tendencia profesional y social que permitan observar los avances y cambios que se han dado y se pueden seguir dando en la sociedad. 
Hacia el establecimiento del perfil del bibliotecólogo a nivel...

Una vez que se cuente con estos estudios para diseñar el perfil será necesario involucrar a todos los participantes del proceso de planificación curricular: docentes, alumnos, egresados, profesionales multidisciplinarios y representantes de empleadores, quienes permitirán lograr una mayor vinculación entre el plan de estudios y los requerimientos sociales.

Los pasos a seguir para la elaboración del perfil son los siguientes:

a) Creación de un mecanismo institucional.- Esto implica a la voluntad política de las autoridades porque el diseño curricular requiere de un equipo de trabajo comprometido con la institución y con la profesión, involucrado en el modelo educativo a seguir y plenamente apoyado por las autoridades de la institución.

b) Marco conceptual.- El equipo de diseño precisa de un marco conceptual pedagógico y de la disciplina en cuestión, con el fin de orientar el perfil y todas las demás actividades.

c) Marco referencial.- Son los estudios que permiten determinar las necesidades del mercado, el análisis de las condiciones económicas y sociales de la región, el país y la sociedad en general, y de la realidad ocupacional. 
Es necesario señalar que el estudio de una práctica profesional, requiere analizar las condiciones económicas, sociales, culturales, políticas, etcétera, que rodean a dicha práctica; por lo menos es ésta la tendencia actual a nivel mundial manifestada en diversos foros de política educativa a nivel nacional e internacional. Es decir, es necesario vincular las estrategias de aprendizaje con el conocimiento y la resolución de problemas que existen en el ejercicio profesional cotidiano, de tal forma que la enseñanza del profesor oriente la labor crítica y analítica del estudiante en formación. De esta forma, los datos concretos de la práctica profesional se utilizarán para determinar los contenidos y experiencias de aprendizaje del diseño curricular.

\section{Perfil bibliotecológico}

Hasta ahora, señala Gordillo: "El perfil tradicional se ha caracterizado por realizar las siguientes actividades técnicas: selecciona, adquiere, cataloga, clasifica y difunde la documentación, trabajando principalmente con material en formato impreso". De esta forma, el trabajo profesional se centraba en la conservación y organización de la información, lo cual se reflejaba en los planes de estudio pero cuando la información se convierte en un elemento dinámico alrededor del cual gira la economía y pro- 
Hacia el establecimiento del perfil del bibliotecólogo a nivel...

ducción de un país, tanto el perfil como los planes tienen que cambiar.

El perfil bibliotecológico requiere de personas capaces de introducirse en el mercado, tanto para influir en la productividad laboral como para generar empleos, en una sociedad que está en constante cambio y que se caracteriza por el desarrollo de las tecnologías de la información y la comunicación (TICs), por la globalización y por el mismo desarrollo disciplinario.

En este momento, en que Internet nos mantiene comunicados con cualquier rincón del mundo y nos coloca ante un cúmulo de información, el bibliotecólogo debe estar en condiciones de enfrentar los nuevos retos que le plantea el mundo y la economía global. Si bien las TICs son una herramienta que facilita las actividades del profesional del área bibliotecológica, también es cierto que éste debe contar con las nuevas habilidades y conocimientos para lograr resultados eficientes en el menor tiempo posible.

La responsabilidad profesional de proporcionarle a la sociedad información confiable, precisa y oportuna sigue siendo una prioridad en el mundo bibliotecológico, el cual exige hoy un perfil profesional que lo refleje a nivel de Iberoamérica, en donde se comparte idioma, condiciones políticas, económicas, sociales y pero también diferencias culturales y educativas; es necesario reflexionar 
Introducción

cuál sería el conjunto de conocimientos, habilidades y aptitudes que permitirían el diseño de planes de estudio que podrían conformar a un profesional de la bibliotecología para un nivel regional, alguien capaz de desenvolverse con la misma calidad profesional en cualquier parte del mundo.

Lina Escalona Ríos 


\title{
El profesional en bibliotecología y documentación: habilidades y competencias
}

\author{
KARLA RODRÍGUEZ SALAS
}

\section{Introducción}

\begin{abstract}
Tos avances tecnológicos han tenido un gran - impacto sobre las bibliotecas y, más aún, sobre los propios bibliotecólogos. El efecto ha sido tan profundo que muchos de los profesionales del sector se están planteando no sólo cuál es la labor que deben desarrollar, sino también cuál sería la forma más correcta de denominar nuestra profesión: bibliotecario, documentalista, profesional de la información, gestor del conocimiento, de la información, científico de la información.

Puede decirse que casi todas las funciones tradicionales del bibliotecario han sufrido transforma-
\end{abstract}


Hacia el establecimiento del perfil del bibliotecólogo a nivel ...

ciones y que además han surgido tareas y nuevos retos. Los bibliotecólogos de hoy en día son consultores, docentes, diseñan sistemas informáticos, dirigen instituciones educativas y, con la aparición de Internet, se han convertido en expertos en búsquedas en la red, en webmasters y hasta en diseñadores de páginas web y de intranets.

Este artículo intenta describir los conocimientos y habilidades que debe aportar la profesión desde la perspectiva de la competencia, para hacer frente al reto que supone la sociedad de la información, teniendo en cuenta que no basta con definir las nuevas funciones del bibliotecario como meros conocimientos técnicos o administrativos. Estas nuevas funciones deben de entenderse como un conjunto de actitudes, aptitudes y puntos de vista que puedan ser rápida y efectivamente aplicados a cualquier nueva oportunidad o necesidad desconocida que pueda surgir.

\section{La educación en la Sociedad de la Información}

A partir de los años setenta aparece una sociedad caracterizada por el incremento de la información, como una definición del mundo moderno. La proliferación de herramientas para generar, almacenar, transmitir y acceder a la información y la constatación de que la "materia prima" más preciada en este 
El profesional en bibliotecología y documentación ...

momento es la propia información, la generación de conocimiento y la capacidad para seguir aprendiendo a lo largo de toda la vida, han llevado a denominar a nuestro tiempo como Sociedad de la Información o Comunicación (Área, 2001).

Castells (1998), en su libro La era de la información, dice que la Sociedad de la Información es el "nuevo sistema tecnológico, económico y social". Una economía en que el incremento de productividad no depende del incremento cuantitativo de los factores de producción (capital, trabajo, recursos naturales), sino de la aplicación de conocimientos e información en la gestión, producción y distribución, tanto en los procesos como en los productos.

Barber (2003), sostiene que: "la característica universal de la moderna Sociedad de la Información es el rol influyente de la Tecnología de Información que permite mejorar la rapidez y la precisión del procesamiento de la información así como transformar la naturaleza de las comunicaciones".

Por otro lado, Pineda (2007) citando a Núñez, manifiesta que el desarrollo de los servicios, de la educación, de la cultura y de todas las esferas de las actividades de la vida humana, dependerán de la información que se tenga, y que la nuestra es una sociedad que necesita que la mitad de la fuerza laboral esté dedicada directamente a la gestión de la información. 
Hacia el establecimiento del perfil del bibliotecólogo a nivel ...

Se ha dicho también que la nuestra es una sociedad inducida a adoptar una nueva organización, caracterizada por la necesidad de información como elemento básico para su funcionamiento en el nuevo contexto tecnológico, social y productivo. Este entorno podría constituir una ventaja para aquellos que no muestren resistencia a los nuevos cambios y que logren asumir los cambios y los conocimientos necesarios para adaptarse.

Las consecuencias de lo descrito anteriormente afectan necesariamente las decisiones respecto al perfil del profesional en bibliotecología y los planes de estudio de las escuelas de bibliotecología, lo que implica una formación continúa que le permita al profesional insertarse de manera equitativa y justa en el nuevo paradigma de la sociedad.

Ante este panorama la formación de los bibliotecólogos, su rol, las funciones y servicios bibliotecarios dependen cada vez más del desarrollo de planes de estudio competentes, acordes a las necesidades del mercado, las cuales demandan el uso de las tecnologías de la información y la comunicación como medio de transmisión del conocimiento.

Considerando los retos que supone la Sociedad de la Información, se puede afirmar que los principales cambios a los que se enfrentan los profesionales en bibliotecología y documentación, se centran en desarrollar un alto nivel de conocimiento sobre 
El profesional en bibliotecología y documentación ...

las nuevas tecnologías de la información y la comunicación, facilitar el acceso y uso de la información al usuario, demostrar habilidades en la gestión y responder a las demandas del mercado laboral.

\section{El currículum académico en la sociedad de la información}

El término currículo lo definen Quesada, Cedeño y Zamora (2001), como "el conjunto de las actividades de aprendizaje, es decir los logros que alcanza el estudiante en función de los objetivos de la educación, complementado con una serie de elementos formales, actitudes, valores y creencias que favorecen y promueven el desarrollo personal y profesional del estudiante".

El currículo también se visualiza como una totalidad en la cual se articulan de manera congruente dos aspectos: la realidad social -dinámica y contradictoria- y la propuesta educativa. Además el currículum se debe entender como una construcción social en la que el sujeto es un ser social, histórico, concreto y reflexivo, que posee un sistema de creencias; construcción en la que existe una relación dialógica entre el docente y el estudiante, donde los alumnos interactúan con otros alumnos, con los profesores y con su propio pensamiento.

Las escuelas de bibliotecología, en especial, la escuela de Bibliotecología y Documentación de la 
Hacia el establecimiento del perfil del bibliotecólogo a nivel ...

Universidad Nacional de Costa Rica, han mantenido un continuo proceso de revisión y desarrollo del plan de estudios, contribuyendo a que los estudiantes adquieran el conocimiento y las competencias necesarias en una sociedad multicultural de la información.

Es por eso que la adopción de una metodología innovadora, activa y experimental resulta fundamental en tanto que el papel del docente y el estudiante se interrelacionan. En este sentido el académico se convierte en guía, mentor y mediador y el estudiante, ejerce el papel protagónico en el proceso de enseñanza-aprendizaje.

Los profesionales saben que deben enfrentar los cambios significativos que el trabajo informacional requiere en esta época y por eso se combinan los intereses cognitivos, técnicos y prácticos al ejecutar el plan de estudios.

El plan de estudios está conformado por cuatro áreas disciplinarias: organización de la información documental; investigación; usuarios/lectores/clientes de la información, y administración de recursos y servicios de información, así como la inclusión de los ejes curriculares de la especialidad y los ejes transversales institucionales. Con respecto a los ejes curriculares de la especialidad éstos son: la tecnología de la información y la comunicación, la gestión de 
El profesional en bibliotecología y documentación ...

unidades de información documental, los métodos y las técnicas de investigación.

De esta manera el plan de estudios facilita el análisis crítico en el estudiante a partir de elaborar investigaciones, aplicar paquetes tecnológicos y utilizar la telemática para organizar, recuperar y transferir la información y las prácticas actuales en las unidades de información documental. Se privilegia, además, la investigación y la resolución de problemas apoyados por la manipulación de paquetes tecnológicos que facilitan la gestión de la información y las prácticas en unidades de información, lo cual propicia la integración del estudiantado en el mercado laboral y favorece la realización de prácticas e investigaciones en el campo profesional. La formación crítica es primordial, y en ella el estudiante se forma para pensar, discutir, crear y trabajar en equipo, para esclarecer puntos de vista y compartir y resolver problemas reales en ambientes laborales.

\section{Perfil del graduado en Bibliotecología y Documentación}

Quesada, Cedeño, Zamora (2001) definen este perfil como el conjunto de competencias que debe poseer el egresado al finalizar la carrera. Por lo tanto tal perfil se encarga de aspectos fundamentales tales como la relación entre la universidad y la sociedad, entre las necesidades sociales y la formación univer- 
Hacia el establecimiento del perfil del bibliotecólogo a nivel ...

sitaria del estudiante y de la adquisición de competencias esenciales para el desempeño profesional.

El término competencia se refiere a la formación de capacidades y disponibilidades permanentes, tanto en el sentido intelectual como en el ético, social y afectivo. Del mismo modo, López-Fé (2002) define a las competencias personales como "un conjunto integrado de destrezas, habilidades, aptitudes, rasgos de personalidad y motivaciones presentes en el comportamiento de una persona que la predisponen a desempeñar con éxito los requisitos y exigencias de actuación de una ocupación en un contexto profesional dado. Villarini, citado por Quesada, Cedeño, Zamora (2001) explica que en términos generales, la naturaleza de las competencias se encuentra definida por los siguientes aspectos:

- Son aprendizajes mayores o comprensivos que resultan de la totalidad de las experiencias educativas formales y no formales.

- Son capacidades que la persona desarrolla gradual y acumulativamente a lo largo del proceso escolar educativo.

- Son características que la persona manifiesta en múltiples situaciones y escenarios variados, y que forman parte de su comportamiento.

- Son características que una comunidad estima como cualidades del ser humano. 
El profesional en bibliotecología y documentación ...

- Son capacidades generales que se desarrollan como parte del proceso de madurez, y retos que la vida le plantea a la persona.

- Son capacidades para llevar a cabo diferentes tareas de manera eficiente y apropiada.

En consecuencia, promover el desarrollo de competencias implica partir de una reflexión sobre la persona, sus experiencias previas y el contexto en que ésta se ubica. Más sencillamente, la palabra competencia se conceptualiza como las características que las personas deben tener para desempeñar un cierto trabajo mejor y de esta manera logran ser mejor apreciadas o valorizadas por la organización.

Chueque, Bazan, Griffero (2004, p.3) identifican las competencias con las características que las personas deben tener para hacer un trabajo mejor y para ser ellas apreciadas o valorizadas por la organización.

Estos autores detallan conjuntamente tres tipos de competencias:

1. Conocimientos claves (saberes).

2. Habilidades (dominio). La suma de conocimientos claves más las habilidades es lo que se designa como aptitudes.

3. Actitudes.

También concluyen lo siguiente: la competencia es la suma de las aptitudes (conocimientos y habilidades) y las actitudes de las personas. 
Hacia el establecimiento del perfil del bibliotecólogo a nivel ...

Desde la perspectiva de las normas basadas en las competencias, el perfil debe reunir las competencias profesionales específicas requeridas para actuar en un área definida. Se trata, pues de la referencia fundamental del currículum, ya que orienta el proceso formativo y especifica las competencias que los estudiantes desarrollarán.

Así, el perfil profesional se convierte en un insumo indispensable para el diseño y selección de las estrategias de enseñanza-aprendizaje, donde las metodologías de enseñanza promueven en el estudiante el desarrollo de capacidades como la argumentación, la reflexión, la toma de decisiones y la resolución de problemas, situaciones que son propias del contexto laboral.

Durante mucho tiempo el perfil del bibliotecólogo respondió a un esquema común y sus tareas se centraban en la selección, adquisición, catalogación, clasificación y difusión de la información. La formación se centraba en el aspecto técnico, en el cuál, según Cornella (1994), la labor del profesional de la información se centraba en la "conservación" de la documentación, quien realizaba tareas de almacenamiento y catalogación, pero cuando la información se consideró como una fuente de valor para la organización, el rol del profesional de la información se tornó dinámico y adquirió mayores matices. 
El profesional en bibliotecología y documentación ...

Para V. Cano (1999), el rol del bibliotecario se ha basado en principios profesionales:

- Es un guardián del fondo bibliotecario y una de sus funciones primordiales es la de adquirir y preservar el patrimonio bibliográfico.

- Es un gestor de sistemas de almacenaje y una de sus funciones principales es la de crear sistemas de ordenamiento para el fondo bibliográfico que tiene en custodia.

- Es un mediador entre los sistemas de ordenamiento y los usuarios. Una de las funciones principales del bibliotecario es facilitar el acceso a la información contenida en la colección que tiene a su cargo.

- El bibliotecario tradicional era autodidacta por falta de enseñanzas oficiales, un conservador y un coleccionista; sin embargo la llegada de las nuevas tecnologías de la información y la comunicación a nuestra sociedad, suponen un cambio radical en el concepto del bibliotecario actual.

Con al advenimiento e incorporación de las nuevas tecnologías en actividades de carácter científico, social, cultural y productivo, el rol del bibliotecólogo ha ido experimentando una transformación en relación con sus funciones y destrezas y éste ha llegado a constituirse en un gestor de información. Este nuevo rol rompe el paradigma de un bibliotecario pasivo, facilitador de información y que demanda 
Hacia el establecimiento del perfil del bibliotecólogo a nivel ...

acciones de mayor impacto y responsabilidad social. Al respecto Coelho (1998) considera que la profesión debe plantearse muy seriamente el cambio de paradigmas largamente sostenidos que no son ya compatibles con las demandas de la sociedad.

Según Aramayo, los bibliotecólogos y documentalistas se enfrentan a cuando menos tres cambios significativos en el modelo de trabajo que realizan:

- La transición del papel a los medios en soporte electrónico como forma predominante de almacenamiento y recuperación de la información.

- La creciente demanda de que los profesionales justifiquen su labor, desde el punto de vista del gasto que supone para la empresa mantener tanto el servicio de documentación como a los propios documentalistas.

- Los nuevos tipos de organización del mercado laboral, como son las fórmulas novedosas como los puestos de trabajo compartidos (job sharing), el teletrabajo (telecommuting), la externalización o outsourcing (contratación de parte del trabajo de la biblioteca con compañías ajenas o externas), las reducciones de personal y la proliferación de trabajos en equipo.

Estos cambios suponen transformaciones en cuanto a su perfil. Muchos profesionales coinciden en la necesidad de que el nuevo profesional debe ser competente en lo que tiene que ver con la gestión y 
El profesional en bibliotecología y documentación ...

organización de conocimientos en varias disciplinas: la formación de usuarios, la educación, la investigación, la administración de recursos y servicios de información y las tecnologías de la información y la comunicación Aunado a esto, debe tener una formación humanística que complemente su formación integral, y además ser innovador, creativo y proactivo.

Barber (2003) expone que la nueva era en la que se está introduciendo la sociedad se caracteriza por la aplicación de las Tecnologías de Información y Comunicación (TIC) en casi todos los aspectos de la vida de las personas; esto replantea la formación de profesionales de la información, y ello deberá analizarse por:

- Desarrollar un alto nivel de conocimiento de las nuevas tecnologías de la información: la facilidad con que la información puede ser almacenada y transmitida electrónicamente unida a la pericia para acceder a ella ilegalmente, requiere de muchas más responsabilidades por parte de los proveedores de servicios de información, quienes tienen en la actualidad un compromiso mayor, no sólo para proteger sus sistemas, sino también para asesorar en lo relativo a derechos de autor.

- Facilitar el acceso y uso de la información: con la aparición de la Web a mediados de los años 90, la información comenzó a estar disponible con 
Hacia el establecimiento del perfil del bibliotecólogo a nivel ...

sólo apretar un botón. Sin embargo, se debe reconocer y aceptar que las nuevas tecnologías ponen a disposición del usuario final, en forma directa, muchos servicios de información.

- Demostrar habilidades de gestión: al hablar de políticas se deben considerar estas habilidades, no sólo en relación con los usuarios, sino en cuanto a la presencia en el ámbito político. En el nivel nacional e internacional es esencial que las políticas de información adoptadas protejan el desarrollo económico, social y las diferencias culturales de todas las naciones.

- Responder a las demandas de un mercado laboral emergente: existen diversas posturas con respecto a la relevancia que este nuevo ambiente tendrá en el mercado de trabajo. Hay quienes confirman que el uso de Internet se incrementará en el futuro. Las computadoras y los hosts de Internet apoyarán la elaboración de productos y servicios multimedia, causarán transformaciones vitales en el sector de contenidos y contribuirán a la difusión de productos electrónicos con mayor rapidez que a la edición de medios impresos. Por otra parte, al hacer referencia al trabajo potencial, Moore (1998) menciona que el uso de las nuevas tecnologías incrementa la eficiencia y la productividad en casi todas las ramas del saber, pero también produce racionalizaciones, lo que 
El profesional en bibliotecología y documentación ...

hace suponer que las ocupaciones tradicionales desaparecerán o se substituirán.

Por otra parte, Castillo (1997), citando a Sánchez, señala que el perfil profesional del bibliotecólogo debe considerar los siguientes aspectos:

- Altos niveles de capacidad en la comunicación personal.

- Habilidad en la administración.

- Manejo de las tecnologías de información.

- Conocimiento de su área de especialidad en la biblioteca.

- Planificación estratégica.

- Visión prospectiva.

- Colaboración y cooperación con quienes generan y proveen información, y desarrollo estratégico que permita la asistencia a los usuarios.

Chacón (2007) menciona los siguientes conocimientos que debería poseer el profesional en bibliotecología y documentación:

- Poseer un entendimiento y un profundo conocimiento de los usuarios/ clientes y de sus necesidades.

- Tener el conocimiento y las destrezas para organizar y preservar la información y permitir así su acceso intelectual.

- Utilizar y estructurar tanto sistemas de información tradicionales como la tecnología de sistemas de información digital. 
Hacia el establecimiento del perfil del bibliotecólogo a nivel ...

Poseer una visión holística de los sistemas de información de manera que integradamente interactúe con la organización, acceso y preservación de la información.

La intención de la Escuela de Bibliotecología y Documentación es ofrecer la oportunidad de adquirir los conocimientos y desarrollar las habilidades y actitudes apropiadas para ejercer un trabajo profesional de calidad, sostenido por un alto nivel de especialización y la capacidad para adaptarse a las transformaciones, requerimientos y a la evolución continua de la Sociedad de la Información.

De esta manera, y coincidiendo con algunos de los autores señalados, se añaden además las siguientes características y habilidades como parte de la formación:

- Desarrollo de la investigación como parte del perfil profesional.

- Formación humanística.

- Manejo de una lengua extranjera, de preferencia el inglés.

- Capacitación permanente (educación continua).

- Apropiación personal del quehacer y el desarrollo de la Institución.

- Empatía con los usuarios de la información.

- Valores éticos e integrales y una buena dinámica.

- Actitud positiva al cambio. 
El profesional en bibliotecología y documentación ...

- Trabajo en equipo y participación interdisciplinaria.

- Educador.

- Compromiso con la excelencia del servicio.

- Creador de productos y servicios innovadores y competitivos.

- Participativo y cooperativo. También es importante tener en cuenta, tal y como lo apunta De la Vega (2005), considerar algunos factores como imprescindibles para enfrentar los cambios venideros:

- Una formación teórica y práctica sólida basada en planes de estudio de pre y posgrado que surjan de la investigación de la realidad, sus necesidades y su proyección.

- Una investigación permanente, en particular, del mercado laboral, que ofrecería información valiosa para conocer la naturaleza cambiante de éste, sus características y proyecciones, y con base en ello tomar decisiones respecto a los planes de estudio y los perfiles profesionales.

- Proyección de la profesión a través de los gremios profesionales y los grupos de trabajo que contribuyan a hacer más visible la profesión y su ámbito de acción.

- Acercamiento universidad-empresa, en el que los estudiantes tengan la oportunidad de poner en práctica los conocimientos adquiridos, así 
Hacia el establecimiento del perfil del bibliotecólogo a nivel ...

como la posibilidad de proyectarse en la comunidad mediante prácticas supervisadas, trabajo social y desarrollo de investigaciones.

\section{Perfil ocupacional y profesional. Escuela de Bibliotecología, Documentación e Informa- ción, Universidad Nacional de Costa Rica}

En el Plan de Bachillerato en Bibliotecología y Documentación de la Escuela de Bibliotecología, Documentación e Información de la Universidad Nacional de Costa Rica, podemos observar como se ofrece la oportunidad de adquirir los conocimientos y desarrollar las habilidades, destrezas y actitudes apropiadas para lograr los perfiles profesionales, como se muestra a continuación: 
El profesional en bibliotecología y documentación ...

\begin{tabular}{|c|c|c|}
\hline $\begin{array}{l}\text { Perfil ocupacional del Di- } \\
\text { plomado en Bibliotecolo- } \\
\text { gía y Documentación }\end{array}$ & $\begin{array}{c}\text { Perfil ocupacional del Bachiller en } \\
\text { Bibliotecología y } \\
\text { Documentación }\end{array}$ & $\begin{array}{l}\text { Perfil ocupacional del Li- } \\
\text { cenciado en Bibliotecolo- } \\
\text { gía y Documentación }\end{array}$ \\
\hline Cargo & Cargo & Cargo \\
\hline $\begin{array}{l}\text { El cargo que desempeñará } \\
\text { será de Asistente o Técnico } \\
\text { en Bibliotecología y Docu- } \\
\text { mentación. }\end{array}$ & \begin{tabular}{|} 
Eestión de la información \\
Gefe de Unidad de Información Documen- \\
tal, Bibliotecólogo profesional y/o Jefe de \\
diferentes secciones de Unidades de \\
Información Documental (bibliotecas, \\
centros de documentación, unidades de \\
información, etcétera). \\
Énfasis: tecnologías de la información y \\
la comunicación \\
चJefe de las secciones de las unidades de \\
información documental relacionadas con \\
las TIC (Tecnología de la Información y \\
de la Comunicación), telecomunicacio- \\
nes, redes, infraestructura tecnológica, y \\
desarrollo de OPAC. \\
- Jefe de la unidad del conocimiento insti- \\
tucional. (Unidad de la Organización que \\
optimiza el capital intelectual (conoci- \\
miento registrado en documentos) de las \\
organizaciones para su beneficio).
\end{tabular} & $\begin{array}{l}\text { El cargo que desempeñará } \\
\text { será: } \\
\boldsymbol{v} \text { Jefe de Unidades de Infor- } \\
\text { mación Documental } \\
\boldsymbol{\nabla} \text { Bibliotecólogo Profesional } \\
\boldsymbol{\nabla} \text { Académico universitario. }\end{array}$ \\
\hline
\end{tabular}




\begin{tabular}{|c|c|c|}
\hline $\begin{array}{l}\text { Perfil ocupacional del Diploma- } \\
\text { do en Bibliotecología y } \\
\text { Documentación }\end{array}$ & $\begin{array}{c}\text { Perfil ocupacional del Bachiller } \\
\text { en Bibliotecología y } \\
\text { Documentación }\end{array}$ & $\begin{array}{c}\text { Perfil ocupacional del Licencia- } \\
\text { do en Bibliotecología y } \\
\text { Documentación }\end{array}$ \\
\hline Fun & Funciones & es \\
\hline $\begin{array}{l}\text { Aplicar normas internacionales } \\
\text { para la descripción física e in- } \\
\text { telectual a los materiales docu- } \\
\text { mentales, en forma manual y } \\
\text { automatizada. } \\
\text { Satisfacer oportuna y eficiente- } \\
\text { mente las necesidades de in- } \\
\text { formación de diferentes tipos } \\
\text { de lectores/usuarios/clientes. } \\
\boldsymbol{v} \text { Integrar los diferentes tipos de } \\
\text { información a nivel de unida- } \\
\text { des de información documen- } \\
\text { tal para instituciones tales } \\
\text { como: archivos, bibliotecas, } \\
\text { museos. } \\
\boldsymbol{v} \text { Aplicar procedimientos electró- } \\
\text { nicos para la gestión de los } \\
\text { procesos de organización. } \\
\boldsymbol{\sigma} \text { Elaborar estadísticas automati- } \\
\text { zadas que permitan evaluar el } \\
\text { alcance de los informes y do- } \\
\text { cumentos publicados en las } \\
\text { instituciones de los diferentes } \\
\text { procesos. } \\
\boldsymbol{n} \text { Controlar el proceso del nuevo } \\
\text { material documental que ingre- } \\
\text { sa a la unidad de información. } \\
\boldsymbol{v} \text { Utilizar la información tecnoló- } \\
\text { gica apropiada para resolver } \\
\text { estrategias de búsqueda y } \\
\text { para crear bases de datos. }\end{array}$ & 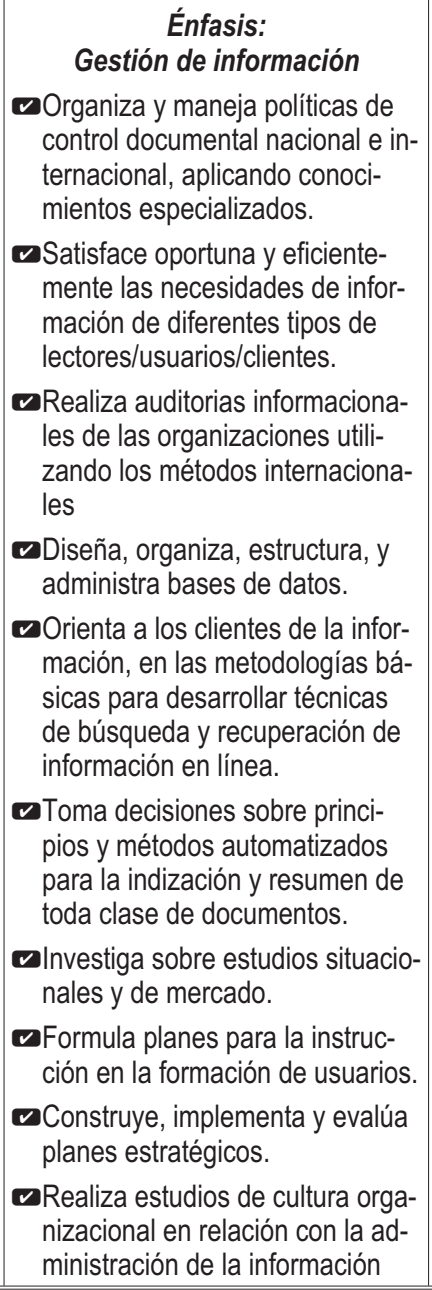 & $\begin{array}{l}\text { vSatisface oportuna y eficiente- } \\
\text { mente las necesidades de in- } \\
\text { formación de diferentes tipos } \\
\text { de lectores/usuarios/clientes. } \\
\text { Asesora, aplica y socializa pa- } \\
\text { quetes tecnológicos para el } \\
\text { manejo de información. } \\
\text { DPlanifica, dirige y coordina uni- } \\
\text { dades de información docu- } \\
\text { mental. } \\
\text { Orienta a los clientes en el uso } \\
\text { de información a nivel nacional } \\
\text { e internacional aplicando la te- } \\
\text { lemática. } \\
\text { DDiseña e implementa redes y } \\
\text { sistemas de información. } \\
\boldsymbol{n} \text { Selecciona y aplica estrategias } \\
\text { que integren la información } \\
\text { como un bien y servicio, selec- } \\
\text { cionando y validando estrate- } \\
\text { gias para la comercialización } \\
\text { de servicios y productos de in- } \\
\text { formación. } \\
\boldsymbol{\nabla} \text { Asesora a los usuarios de in- } \\
\text { formación en las nuevas for- } \\
\text { mas y condiciones de acceso a } \\
\text { servicios y productos de infor- } \\
\text { mación existentes a nivel na- } \\
\text { cional e internacional. } \\
\text { Logra una capacidad de auto- } \\
\text { gestión de las Unidades de } \\
\text { Información Documental }\end{array}$ \\
\hline
\end{tabular}


El profesional en bibliotecología y documentación ...

\begin{tabular}{|c|c|c|}
\hline $\begin{array}{c}\text { Perfil ocupacional del Diploma- } \\
\text { do en Bibliotecología y } \\
\text { Documentación }\end{array}$ & $\begin{array}{c}\text { Perfil ocupacional del Bachiller en } \\
\text { Bibliotecología y } \\
\text { Documentación } \\
\text { (Cont.) }\end{array}$ & $\begin{array}{c}\text { Perfil ocupacional del Licen- } \\
\text { ciado en Bibliotecología y } \\
\text { Documentación }\end{array}$ \\
\hline Funciones & Funciones & Funciones \\
\hline & 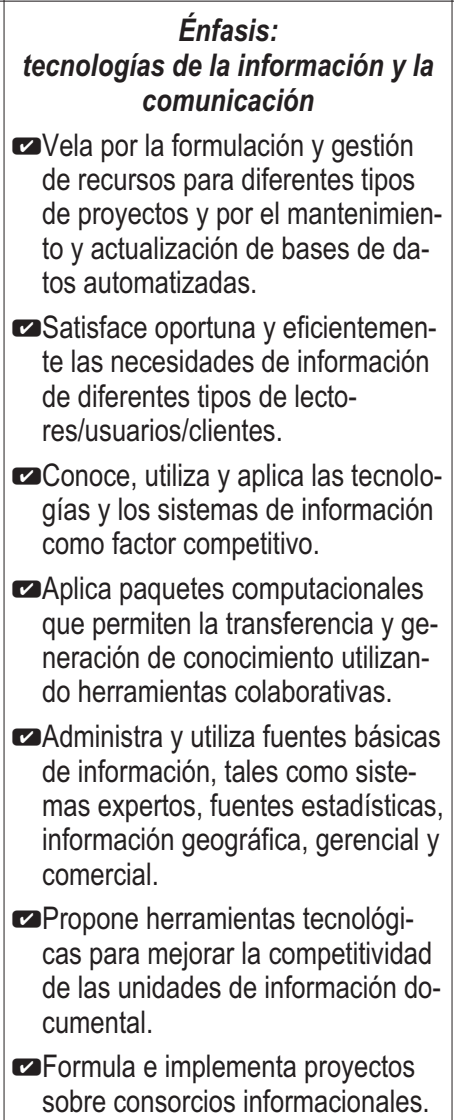 & \\
\hline
\end{tabular}




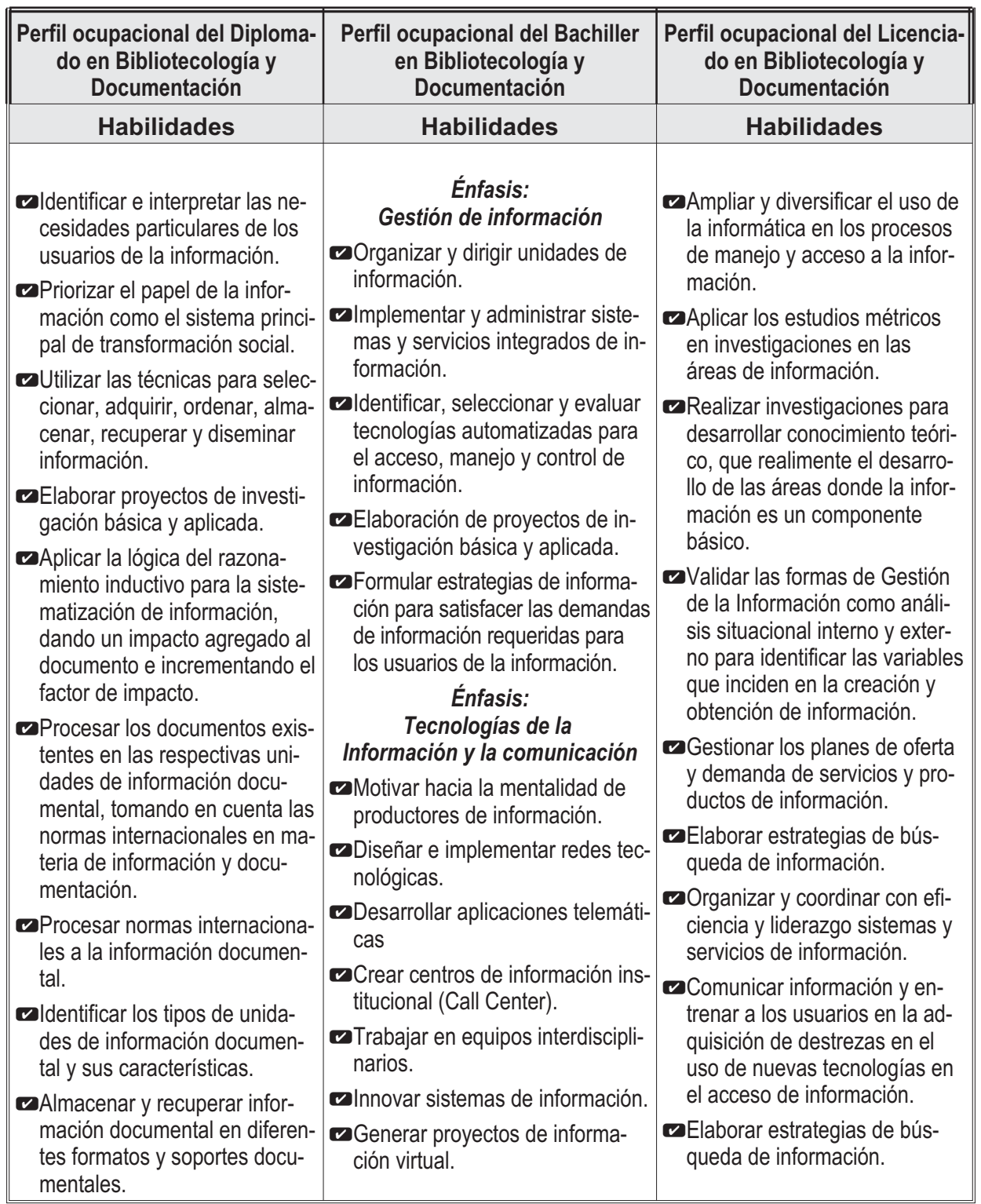




\begin{tabular}{|c|c|c|}
\hline $\begin{array}{c}\text { Perfil ocupacional del Diplo- } \\
\text { mado en Bibliotecología y } \\
\text { Documentación }\end{array}$ & $\begin{array}{c}\text { Perfil ocupacional del Bachiller en } \\
\text { Bibliotecología y } \\
\text { Documentación } \\
\text { (Cont.) }\end{array}$ & $\begin{array}{c}\text { Perfil ocupacional del Licencia- } \\
\text { do en Bibliotecología y } \\
\text { Documentación }\end{array}$ \\
\hline Habilidades & Habilidades & Habilidades \\
\hline $\begin{array}{l}\text { Elaborar bases de datos so- } \\
\text { bre contenidos temáticos. } \\
\text { Diseminar información a los } \\
\text { lectores/usuarios/clientes } \\
\text { meta. } \\
\text { Manipular y aplicar paquetes } \\
\text { tecnológicos en los procesos } \\
\text { básicos de las actividades en } \\
\text { las unidades de información } \\
\text { documental. }\end{array}$ & $\begin{array}{l}\boldsymbol{\nabla} \text { Administrar el conocimiento infor- } \\
\text { macional de la organización . } \\
\boldsymbol{\sigma} \text { Digitalizar parte de la memoria del } \\
\text { mundo. } \\
\boldsymbol{\nabla} \text { Integrar soluciones regionales } \\
\text { (consorcios, convenios) que facili- } \\
\text { ten la comunicación entre los pro- } \\
\text { fesionales e instituciones. } \\
\boldsymbol{v} \text { Investigar sobre el desarrollo de } \\
\text { las aplicaciones tecnológicas en el } \\
\text { campo de la información documen- } \\
\text { tal. } \\
\boldsymbol{\nabla} \text { Realizar aplicaciones informáticas } \\
\text { para las diferentes tareas de las } \\
\text { unidades de información docu- } \\
\text { mental. }\end{array}$ & $\begin{array}{l}\boldsymbol{v} \text { Organizar y coordinar con efi- } \\
\text { ciencia y liderazgo sistemas y } \\
\text { servicios de información. } \\
\boldsymbol{v} \text { Comunicar información y en- } \\
\text { trenar a los usuarios en la ad- } \\
\text { quisición de destrezas en el } \\
\text { uso de nuevas tecnologías en } \\
\text { el acceso de información. } \\
\boldsymbol{v} \text { Integrar redes y sistemas de } \\
\text { información. } \\
\boldsymbol{v} \text { Trabajar en equipos interdisci- } \\
\text { plinarios. } \\
\boldsymbol{v} \text { Buscar la asociación y las } \\
\text { alianzas estratégicas para la } \\
\text { organización de redes de infor- } \\
\text { mación documental. } \\
\boldsymbol{v} \text { Dirigir y evaluar sistemas de } \\
\text { información documental. } \\
\boldsymbol{v} \text { Planificar y organizar unidades } \\
\text { de información documental. }\end{array}$ \\
\hline
\end{tabular}




\begin{tabular}{|c|c|c|}
\hline $\begin{array}{l}\text { erfil ocupacional del Diplomado } \\
\text { en Bibliotecología y } \\
\text { Documentación }\end{array}$ & $\begin{array}{l}\text { Perfil ocupacional del Bachi- } \\
\text { Iler en Bibliotecología y } \\
\text { Documentación }\end{array}$ & $\begin{array}{c}\text { Perfil ocupacional del Licencia- } \\
\text { do en Bibliotecología y } \\
\text { Documentación }\end{array}$ \\
\hline & & \\
\hline 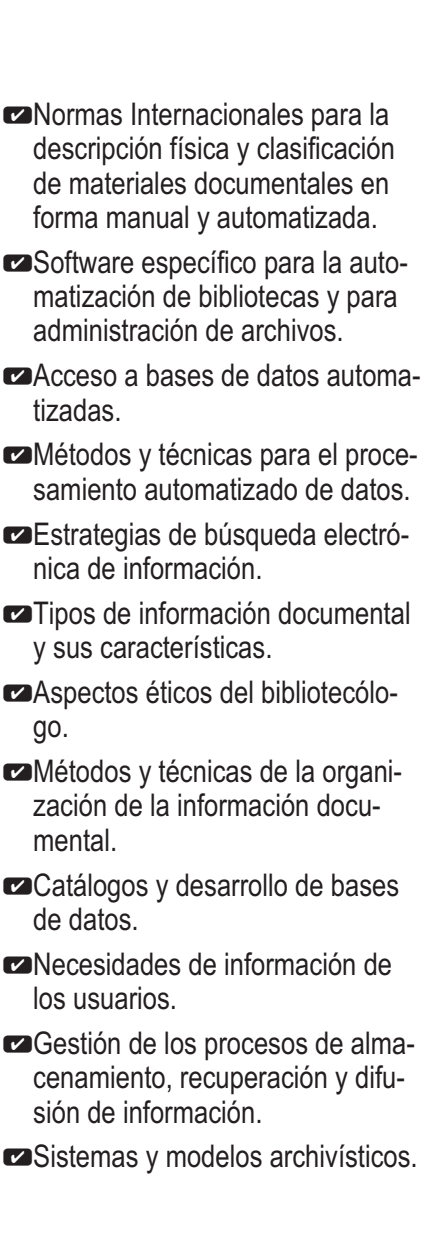 & $\begin{array}{c}\text { Énfasis: } \\
\text { Gestión de información } \\
\boldsymbol{v} \text { Software específico para el di- } \\
\text { seño, estructuración y organi- } \\
\text { zación de bases de datos au- } \\
\text { tomatizadas. } \\
\boldsymbol{\nabla} \text { Tecnologías automatizadas } \\
\text { para indicar y resumir material } \\
\text { documental. } \\
\boldsymbol{\nabla} \text { Normas internacionales para } \\
\text { el procesamiento automatiza- } \\
\text { do de información. } \\
\boldsymbol{v} \text { Investigación básica y aplica- } \\
\text { da para el desarrollo de áreas } \\
\text { que tengan como elemento } \\
\text { básico la información. } \\
\text { Énfasis: } \\
\text { Tecnologías de la información } \\
\text { y la comunicación } \\
\boldsymbol{\nabla} \text { Software específico para el di- } \\
\text { seño, estructuración y organi- } \\
\text { zación de bases de datos au- } \\
\text { tomatizadas. } \\
\boldsymbol{\nabla} \text { Tecnologías automatizadas } \\
\text { para indizar y resumir material } \\
\text { documental. } \\
\boldsymbol{\nabla} \text { Normas internacionales para } \\
\text { el procesamiento automatiza- } \\
\text { do de información documen- } \\
\text { tal. } \\
\boldsymbol{v} \text { Nuevas formas y condiciones } \\
\text { de acceso a servicios y pro- } \\
\text { ductos de información. }\end{array}$ & $\begin{array}{l}\boldsymbol{v} \text { Gestión administrativa en uni- } \\
\text { dades de información docu- } \\
\text { mental. } \\
\boldsymbol{v} \text { Gestión automatizada para el } \\
\text { manejo de bases de datos, re- } \\
\text { cursos digitales, documentos } \\
\text { audiovisuales y archivos digita- } \\
\text { les, entre otros. } \\
\boldsymbol{v} \text { Convenios, leyes, derecho de } \\
\text { autor, propiedad intelectual, } \\
\text { mercadeo de servicios y pro- } \\
\text { ductos de información. } \\
\boldsymbol{v} \text { Establecimiento de convenios } \\
\text { nacionales e internacionales } \\
\text { para la transferencia de infor- } \\
\text { mación a través de redes y sis- } \\
\text { temas de información. } \\
\boldsymbol{\sigma} \text { Técnicas normalizadas para el } \\
\text { procesamiento, difusión y dis- } \\
\text { tribución de información apli- } \\
\text { cando normas internacionales. } \\
\boldsymbol{v} \text { Recursos específicos para el } \\
\text { diseño y la realización de pro- } \\
\text { yectos específicos de investi- } \\
\text { gación, en las áreas de la bi- } \\
\text { bliotecología y la } \\
\text { documentación. } \\
\boldsymbol{v} \text { Capacidad organizativa para } \\
\text { desarrollar planes de merca- } \\
\text { deo de los servicios y produc- } \\
\text { tos de información. }\end{array}$ \\
\hline
\end{tabular}


El profesional en bibliotecología y documentación ...

\begin{tabular}{|c|c|c|}
\hline $\begin{array}{c}\text { Perfil ocupacional del Diploma- } \\
\text { do en Bibliotecología y } \\
\text { Documentación }\end{array}$ & $\begin{array}{c}\text { Perfil ocupacional del Bachiller } \\
\text { en Bibliotecología y } \\
\text { Documentación } \\
\text { (Cont.) }\end{array}$ & $\begin{array}{c}\text { Perfil ocupacional del Licencia- } \\
\text { do en Bibliotecología y } \\
\text { Documentación }\end{array}$ \\
\hline Conocimiento & Conocimiento & Conocimiento \\
\hline $\begin{array}{l}\text { vequetes tecnológicos en la } \\
\text { aplicación de procesos docu- } \\
\text { mentales }\end{array}$ & $\begin{array}{l}\boldsymbol{v} \text { Investigación básica y aplicada } \\
\text { para el desarrollo de áreas que } \\
\text { tengan como elemento básico la } \\
\text { información. } \\
\boldsymbol{v} \text { Comercialización y mercadeo de } \\
\text { información impresa y electróni- } \\
\text { ca } \\
\boldsymbol{v} \text { Administración y uso de fuentes } \\
\text { básicas de información, tales } \\
\text { como sistemas expertos, fuentes } \\
\text { estadísticas, información geográ- } \\
\text { fica, gerencial, comercial. } \\
\boldsymbol{v} \text { Diseño y elaboración de bases } \\
\text { de datos documentales } \\
\boldsymbol{\sigma} \text { Evaluación de paquetes tecnoló- } \\
\text { gicos integrados para los diferen- } \\
\text { tes procesos documentales. } \\
\boldsymbol{v} \text { Elaboración de catálogos elec- } \\
\text { trónicos de los diferentes acer- } \\
\text { vos documentales. } \\
\boldsymbol{v} \text { Construcción de modelos para la } \\
\text { recuperación de la información. } \\
\boldsymbol{v} \text { Aplicación de formatos docu- } \\
\text { mentales internacionales para la } \\
\text { creación de bases de datos. }\end{array}$ & \\
\hline
\end{tabular}


Hacia el establecimiento del perfil del bibliotecólogo a nivel ...

\begin{tabular}{|c|c|c|}
\hline $\begin{array}{c}\text { Perfil ocupacional del Diploma- } \\
\text { do en Bibliotecología y } \\
\text { Documentación }\end{array}$ & $\begin{array}{c}\text { Perfil ocupacional del Bachiller } \\
\text { en Bibliotecología y } \\
\text { Documentación }\end{array}$ & $\begin{array}{c}\text { Perfil ocupacional del Licencia- } \\
\text { do en Bibliotecología y } \\
\text { Documentación }\end{array}$ \\
\hline Actitudes & Actitudes & Actitudes \\
\hline $\begin{array}{l}\boldsymbol{v} \text { Servicio. } \\
\boldsymbol{v} \text { Innovación. } \\
\boldsymbol{\sigma} \text { Ética profesional. } \\
\boldsymbol{\sigma} \text { Competitividad. } \\
\boldsymbol{\sigma} \text { Trabajar en equipos interdisci- } \\
\text { plinarios. } \\
\boldsymbol{\sigma} \text { Mentalidad abierta al cambio. } \\
\boldsymbol{\sigma} \text { Flexibilidad. } \\
\boldsymbol{\sigma} \text { Positivismo ante los nuevos re- } \\
\text { tos. }\end{array}$ & 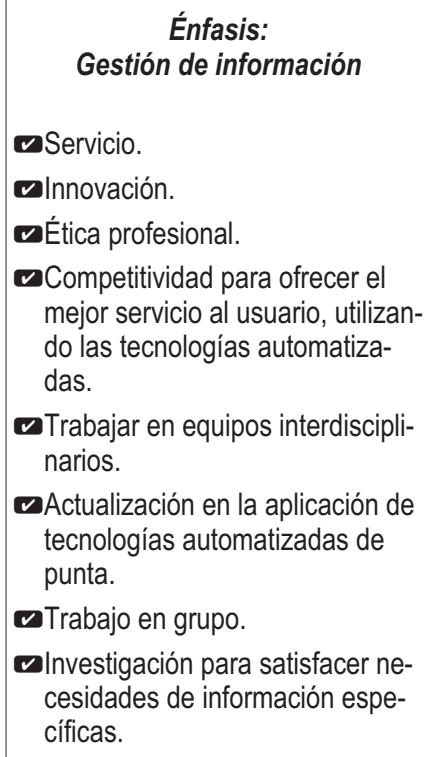 & 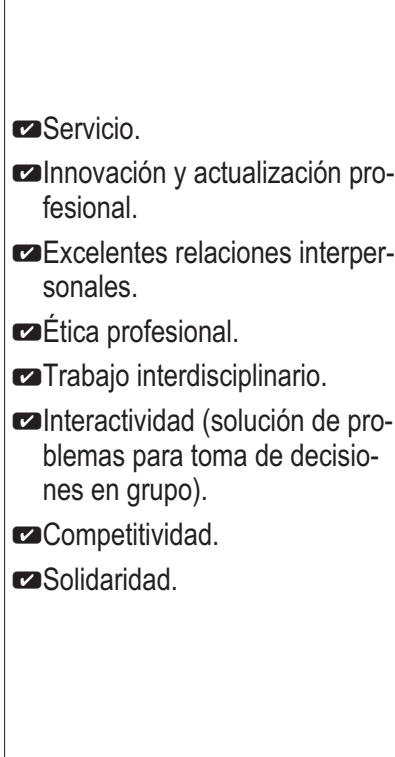 \\
\hline
\end{tabular}


El profesional en bibliotecología y documentación ...

\begin{tabular}{|c|c|c|}
\hline $\begin{array}{l}\text { Perfil ocupacional del Diploma- } \\
\text { do en Bibliotecología y } \\
\text { Documentación }\end{array}$ & $\begin{array}{l}\text { Perfil ocupacional del Bachiller } \\
\text { en Bibliotecología y } \\
\text { Documentación } \\
\text { (Cont.) }\end{array}$ & $\begin{array}{c}\text { Perfil ocupacional del Licencia- } \\
\text { do en Bibliotecología y } \\
\text { Documentación }\end{array}$ \\
\hline Actitudes & Actitudes & Actitudes \\
\hline & 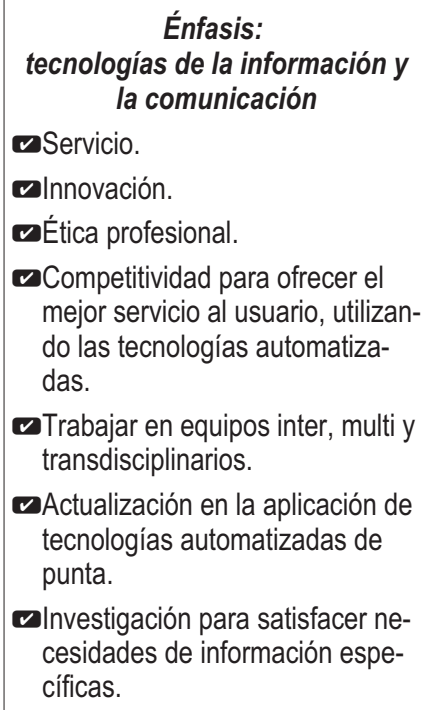 & \\
\hline
\end{tabular}

Fuente: Universidad Nacional (Costa Rica). Facultad de Filosofía y Letras. Escuela de Bibliotecología Documentación e Información. (2004). Plan de estudios de Licenciatura y Bachillerato en Bibliotecología y Documentación con salida lateral de Diplomado. Heredia, C,R. : UNA. 
Hacia el establecimiento del perfil del bibliotecólogo a nivel ...

\section{Conclusiones}

El importante papel que deben desempeñar los y las bibliotecólogos en la sociedad actual representa un reto difícil pero no imposible. Su formación constituye una obligación para quienes nos desempeñamos como docentes, quienes tenemos la obligación de hacer realidad la formación de profesionales íntegros, competitivos y comprometidos con las necesidades que demanda la sociedad de la información.

Tal y como lo expresa López, el profesional de la información debe ser un agente de cambio, capaz de contribuir con su esfuerzo cotidiano e incansable a la creación de una clara conciencia institucional acerca de la importancia del recurso de la información, como materia prima del desarrollo social y económico de un país.

\section{Referencias bibliográficas}

Aramayo, A., La labor profesional de los bibliotecarios y documentalistas en el siglo XXI, disponible en: http://www.sla.org/content/professional/meaning /compsp.cfm Consultado: 23/03/07.

Area, A (Coord.) (2001), Educar en la sociedad de la información, Bilbao, Derclée de Brouwer. 
El profesional en bibliotecología y documentación ...

Barber, Elsa (2003), "Reorientando la Educación en Bibliotecología y Ciencia de la Información para la Sociedad de la Información: algunas Reflexiones”, Ponencia presentada en Metáforas de la Sociedad de la Información en el Contexto Latinoamericano y del Caribe. Heredia : UNA, 16 - 18 junio.

Castells, M (1998), La era de la información: economía, sociedad y cultura, Madrid : Alianza Editorial.

Castillo, O. (1997), "El profesional de la información”, en $A I B D A, 18$ (2): 81-85.

Chacón, L (2007), "El profesional de la información: oportunidades laborales y desarrollo profesional", en el I Congreso Internacional y VI Congreso Nacional de Bibliotecarios, Documentalistas y Archivistas, Paraguay.

Chueque, M G, de Valle Bazán, I y Griffero, M M (2004), "La evaluación por competencias", en el VII Encuentro de Directores y VI Encuentro de Docentes de Escuelas de Bibliotecología y Ciencias de la Información del MERCOSUR. Mar del Plata, Argentina.

Coelho Neto, José Teixeira de (1997), “As duas crises da biblioteconomia”, en Transinformacao, 9 (1), 28. 
Hacia el establecimiento del perfil del bibliotecólogo a nivel ...

Consejo de Directores de la Special Libraries Association (2003). Competencias para profesionales de la Información en el siglo XXI, disponible en http://www.sla.org/content/learn/comp.2003 /compspanish.cfm. Consultado: 27/03/2007

Cornella A (1994), Los recursos de información: ventaja competitiva de las empresas, Madrid: McGraw-Hill.

De la Vega , A. (2005), "El mercado laboral y la formación de los bibliotecólogos", en Bibliotecas, 22(3). 5-22.

López-Fe Figueroa, C M (2002), Persona y profesión: procedimientos y técnicas de selección y orientación, Madrid, TEA Ediciones.

Mité on Information Literacy, (1989), Final report, [en línea] http://www.ifla.org./IV/ifla69/papers/199ewebber.pdf. Consultado: 20/03/2007.

Pérez, M., Herrera, J. (2006), Teoría y nuevos escenarios de la biblioteconomía, ${ }^{\mathrm{a}}$. ed., Buenos Aires, Alfagrama.

Pineda, J. M., El rol del bibliotecólogo en la sociedad de la información, disponible en:

http://www.eprints.rclis.org. Consultado: 20/03/ 07. 
El profesional en bibliotecología y documentación ...

Quesada, M , Cedeño, M y Zamora, J. (2001), El diseño curricular en los planes de estudio: aspectos teóricos y guía metodológica, Heredia, C.R., EUNA.

Rodríguez Sánchez Y, Mesa Fleitas ME, Álvarez Solórzano E., La ética del profesional de la información ante la nueva sociedad del conocimiento, Acimed 2006;14(1), disponible en: http://bvs.sld.cu/revistas/aci/vol14_1_06/aci 12106. htm Consultado: 15/03/07.

Universidad Nacional (Costa Rica). Facultad de Filosofía y Letras. Escuela de Bibliotecología Documentación e Información. (2004), Plan de Estudios de la Carrera Licenciatura y Bachillerato en Bibliotecología y Documentación con salida lateral de Diplomado. Heredia, C.R., La Universidad.

Vega de Arza, A. (2005), "El mercado laboral y la formación de los bibliotecólogos", en Bibliotecas 22, (3). 


\title{
Conocimiento tecnológico para el desarrollo de la actividad profe- sional en Bibliotecología y Documentación
}

\author{
JUAN CARLOS MARCOS RECIO
}

Educar a las nuevas generaciones es mucho más que cambiar libros por pantallas o monitores de computadora, se requiere conjugar lo mejor de la tradición y de la experiencia pedagógica con las nuevas opciones tecnológicas y conciliar la educación formal con las prácticas cotidianas de la comunicación a distancia.

Josefina Vázquez Mota (Secretaria de Educación Pública)

\section{Introducción}

omo cada comienzo de siglo, el actual se pre-
sentó como una época de grandes transforma-
ciones ya despuntadas en los últimos años de la
centuria anterior. El motor de cambio más signifi-
cativo es y será, al menos durante una década más,
la información. Entendida ésta como elemento de
transmisión de noticias como referente en las áreas
profesionales y personales, en las que el trabajo del


Hacia el establecimiento del perfil del bibliotecólogo a nivel ...

bibliotecario y documentalista experimentará un cambio significativo. Consecuentemente, la formación de estos profesionales se verá modificada por las demandas de la propia sociedad y también por los factores externos que inducen a crear modelos educativos más actuales y con mayor valor para la sociedad.

Algunas de estas nuevas situaciones requerirán un tiempo de implementación; como sucede con frecuencia, el deseo va por delante de la realidad. En este texto pretendemos mostrar cómo adaptar esa situación para hacerla más dinámica y eficaz para los bibliotecarios y los documentalistas, y ofrecer una serie de recomendaciones para aplicar la actual tecnología en la docencia.

A estas alturas de la tecnología, el concepto de novedad ha perdido su valor. El ritmo en el que se desenvuelven las cosas implica que el espacio físico y temporal se acorta cada día más. La cultura del libro es la única que ha conseguido sobrevivir a todas. Y tras el libro llegaron los periódicos y las revistas. La fotografía dejó espacio a la creatividad del cine: la imagen en movimiento frente a la imagen fija. Luego llegó la radio y, cómo no, la televisión, y muchos creyeron que el cine tocaría a su fin; y no es así. Ahora está Internet, y el único peligro es que todas las comunicaciones convergen hacia ese sitio real y virtual en el que millones de espectadores se dan cita cada día 
Conocimiento tecnológico para el desarrollo de la actividad ...

para trabajar, ver, soñar, estudiar, crear, copiar... Y eso durante muchos siglos fue tarea de la biblioteca.

Pretendemos, pues, hablar de la tecnología en la documentación y en las bibliotecas, pero también en el ámbito que da origen a la formación de los profesionales que trabajan en estas áreas, ya que, sin ellos, la sociedad sería diferente. El saber ha estado en sus manos desde hace cientos de años ¿Podrá seguir estando en el futuro? ${ }^{1}$

\section{¿Hacia donde camina la sociedad?}

El desarrollo de la tecnología no siempre es parejo al de la actividad educativa; hay un desfase que técnicamente se ha llamado la brecha digital, pero que va más allá. No sólo es difícil acceder a la tecnología

1 Véase además otros artículos recientes del autor:

Marcos Recio, Juan Carlos (2005), Herramientas docentes al servicio de la biblioteconomía mexicana, México: UNAM., Coloquio de Investigación Bibliotecológica y de la información (2004: México, D.F.) pp. 231-242.

- Marcos Recio, Juan Carlos (2006), Estrategias para crear, formary evaluar usuarios virtuales en la sociedad del conocimiento. Guadalajara, Jalisco, Universidad de Guadalajara, Coloquio Internacional de Bibliotecarios (12: 2005: Guadalajara, Jalisco) pp: 99-12.

- Marcos Recio, Juan Carlos (2006), "Hacia la educación a distancia en la bibliotecología: algunas propuestas en México y en España”, México: Universidad Nacional Autónoma de México, CUIB, en: Investigación Bibliotecológica: archivonomía e información, 2006-Vol 20, Num. 40, pp: 73-120. 
Hacia el establecimiento del perfil del bibliotecólogo a nivel ...

por la carencia de equipos informáticos, también lo es por la escasa formación de personas

La mayoría de las personas confían en los aparatos tecnológicos una vez que son sencillos, fáciles de manejar y de usar, y no les suponen muchos problemas. El miedo a lo desconocido es un acto connatural al ser humano, pero también es recurrente el estado constante de evolución para mejorar en todos los campos. En este sentido, un libro que recoge de forma sencilla ese recorrido por la tecnología es Del hacha al Chip. Cómo las tecnologías cambian nuestra mente. Quizás, deberíamos preguntarnos como los autores: ¿qué se pierde y qué se gana en ese recorrido? o ¿a qué renunciamos a cambio del uso y consumo de la tecnología?

Dentro de la sociedad consumista en la que viven la mayoría de los países desarrollados, la tecnología es un factor decisivo: hay que tener la última generación de móvil (o teléfono celular), la lavadora más reciente y además el mejor y más apabullante de los televisores. La gente vive por y para el desarrollo tecnológico. Hay excepciones muy honrosas pero siguen contemplando una minoría luchadora que es capaz de frenar ese consumismo. En el resto de las sociedades esta evolución ha roto los paradigmas de desarrollo y crecimiento. Así, ciertos países considerados del tercer mundo, alcanzaron antes una gran cuota de mercado en consumo de Internet 
Conocimiento tecnológico para el desarrollo de la actividad ...

$y$, sobre todo en teléfonos celulares, que algunos países que consideramos como ricos.

Con este panorama, el siglo XXI ofrece un mapa desigual del consumo de tecnología. Por eso conviene tener presente el estudio que hicieron ya hace varios años los profesores Lyman y Varian, de la Universidad de Berkeley. En concreto, en el 2003 señalaban: "[...]la producción [de información] en el mundo alcanza la suma total de 2,120,000 terabytes" (Lyman; Varian 2003); lo que representa millones de libros, documentos, periódicos, material de oficina y últimamente, imágenes, muchas imágenes en vídeo. Tomemos como ejemplo la reciente compra de YouTube por Google como una experiencia que nos muestra cómo se reparte la información a través de videos en la red Internet.

Si nos acercamos al mundo de la educación se ha constatado ya que el elemento más significativo que demuestra la importancia de una comunidad en el ámbito internacional es la capacidad de lectura de sus ciudadanos, traducida en un nivel educativo en el que los analfabetos son cada vez menos, tanto los que no sabían leer entonces como los analfabetos digitales de ahora. Así reconocemos junto con Inés Lozano que la sociedad debe mejorar para no quedar en condiciones inferiores que crean brechas digitales y capas marginadas de la tecnología: 
Hacia el establecimiento del perfil del bibliotecólogo a nivel ...

La cultura digital si bien es algo nuevo para quienes escribimos desde los países del tercer mundo, es algo con lo cual debemos estar conectados e identificarnos, de lo contrario la masa nos arrastrará dejándonos al margen de la evolución (Lozano, 2002).

El punto de partida es claro en algunas regiones de Latinoamérica, entre ellas México: Educación Para Todos (EPT); ésa es la prioridad, luego ya llegará la hora de la tecnología. En este sentido, la UNESCO, a través del Proyecto Regional de Educación para América Latina y el Caribe (PRELAC), pretende avanzar hacia el logro de una educación de calidad para todos. Este proyecto se inició en La Habana, en el 2002, y su siguiente cumbre fue hacia finales de marzo del 2007 en Buenos Aires. En esta ciudad se dieron cita treinta ministros de educación de Latinoamérica para avanzar en el compromiso de EPT y de calidad. En el caso de México, algunos factores indican que la educación está sufriendo rezagos. Así, al presentar el libro: Educación en México: una propuesta ciudadana, la directora de la oficina Regional de la Organización de Estados Iberoamericanos para la Educación la Ciencia y la Cultura, Karen Kovacs, estableció que el sistema necesita nuevas reglas para operar; habría que hacerlo más ágil y menos burocrático. La autora indicó además que: “Al hacer un balance de 2000 a 2006 se registraron retrocesos sensibles respecto a 2003 , 
Conocimiento tecnológico para el desarrollo de la actividad ...

además de que un tercio de la población nacional tiene un rezago en la materia por la falta de cobertura o ineficiencia del sistema educativo". En similares parámetros se explicó Pablo Latapí Sarré, del Instituto de Investigación sobre la Universidad y la Educación de la UNAM, quien consideró que debe haber un cambio de visión para enfrentar los rezagos educativos que aún existen en el país, y aseguró que esa exigencia debe ir más allá de las reglas de la democracia.

El último paso antes de sacar conclusiones es la situación hacia la que camina la sociedad es la relación índice de lectura enfrentada a consumo de tecnología. En el caso de México esa relación es más notoria. En cifras difundidas por la UNESCO, el índice de lectura de México señala tan sólo 1.2 libros al año por persona, cuando el organismo ha recomendado la lectura de cuatro textos para un sano desarrollo de la sociedad. En México no se lee ni a Kafka, ni a Shakespeare, ni a Kundera, pero en contraste otras publicaciones semanales como El libro vaquero o TV Notas superan el medio millón de impresiones.

Sin embargo, la Secretaría de Educación Pública (SEP) ofrece otros datos más esperanzadores:

En el marco del Programa Nacional Hacia un País de Lectores, entre septiembre de 2005 y agosto de 2006 se llevaron a cabo 299 mil 576 actividades de fomento a la lectura para niños y 
Hacia el establecimiento del perfil del bibliotecólogo a nivel ...

jóvenes, como son la instalación de la Carpa Jóvenes en la Feria Internacional del Libro Infantil y Juvenil en la ciudad de México (SEP, 2007).

Si ahora nos trasladamos, el consumo digital, el uso de Internet y el de la tecnología, se puede intuir cómo serán los nuevos profesionales y cómo ha de actuar la educación para preparar el camino de éstos. Uno de los organismos que estudia el consumo de tecnología en México es la Asociación Mexicana de Internet (AMIPCI), la que en su último informe sobre los "Hábitos de los usuarios de Internet en México 2006", dado a conocer por Adriana Peña, Vicepresidenta de Investigación de Mercado de la Dirección Comercial Televisa Digital, señala que hay ya 7,4 millones de computadoras que tienen acceso a Internet, de las 12,5 millones de computadores personales que existen en México.

Otros datos significativos son los 53,4 millones de teléfonos celulares y 1.3 millones de handhelds. Además, el $60 \%$ de las computadoras instaladas en México está en los hogares, el 58\% de los cuales tienen Internet.

Sin los datos de consumo de tecnología, sin conocer la realidad de ésta y las posibilidades que tienen los usuarios de actuar e interactuar, es difícil planificar estudios en los que se les pida a los alumnos que desarrollen esas funciones. La universidad recibe miles de alumnos cada año, de diferentes es- 
Conocimiento tecnológico para el desarrollo de la actividad ...

tamentos sociales y de varias regiones geográficas, por lo que tiene la misión de formar profesionistas que desarrollen actividades que la sociedad demanda. En el caso de México, la tasa de penetración nacional de Internet en personas mayores de 6 años es de $21.1 \%$, lo que indica que las futuras generaciones llegarán a la universidad con un mejor nivel tecnológico. Por lo pronto según AMIPCI, existen ya 20.2 millones de internautas mayores de 6 años a nivel internacional.

En todo caso las cifras oficiales sobre la lectura indican que México avanza en este sentido y se constatan algunos indicios de mejora. Sin la lectura los docentes encuentran un hueco difícil de taponar porque el perfil docente es muy limitado y la formación humanística de los alumnos muy escasa. El desarrollo educativo requiere de formaciones intermedias que impliquen criterios que orienten a los alumnos hacia una lectura recogida, interior y descriptiva que les permita entender la educación superior.

\section{Tecnología para formar e informar: misión y visión de algunos autores}

Una mirada hacia atrás en la historia muestra ejemplos de avances lentos pero significativos en el mundo de la educación. Sólo ciertas reformas impulsadas desde ámbitos religiosos frenaron el avan- 
Hacia el establecimiento del perfil del bibliotecólogo a nivel ...

ce de ésta. En cada una de las etapas, el pensamiento fue ofreciendo ideas y metodologías que tienen un punto de inflexión con la Revolución Francesa y la llegada de la Razón. El planteamiento religioso deja paso a razonamientos para entender las cosas desde perspectivas alejadas de Dios.

En la actualidad los planteamientos son diversos, el punto de partida sería: ¿Hay tecnología suficiente para formar personas? ¿Quién dispone de la tecnología? ¿Los docentes están a la altura para hacer propuestas educativas ayudadas por la tecnología? $¿$ Son conscientes los alumnos de que sin ella, su preparación sería diferente y que su ámbito profesionista quedaría limitado? Estas interrogaciones no esconden sino la situación actual a la que se enfrentan los docentes y los alumnos.

Claro está que hay también opciones intermedias. No todo es tecnología, ni ausencia total de ella. El avance civilizatorio está marcado por el consumo de cualquier tipo de invento, pero siempre de manera complementaria al desarrollo de una actividad que tiene una aplicación práctica. Sin embargo, la educación no siempre puede traducirse en elementos prácticos, eso queda para quienes desarrollarán una actividad con posterioridad. La educación aporta elementos humanos y sociales que en conjunto posibilitan que una sociedad avance; no es que se materialicen sino que ellos mismos sirven 
Conocimiento tecnológico para el desarrollo de la actividad ...

como lanzadera para que otros individuos descubran nuevas formas de convivir y mejorar socialmente.

En medio de esas dos posturas se encuentra el equilibrio necesario para que tanto docentes como alumnos encuentren que las formas clásicas de enseñar siguen vigentes y son actuales, y que si además si éstas se retoman y complementan con el uso y el consumo de la información, los resultados finales serán necesariamente elevados en ambos lados del mundo académico. El principal problema al que se enfrentan hoy en día los docentes es la falta de tiempo para la lectura, la reflexión y la investigación. En la mayoría de las ocasiones, esa reflexión llega como fruto del trabajo educativo con los alumnos, en tanto que ambas partes acceden de manera más sencilla a una gran cantidad de información que ponen en común para el ejercicio académico.

Algunos autores como Manuel Castell, Alvin Toffler, Saskia Sassen, Yoneji Masuda, John Naisbitt o James Martin, creen que la tecnología se ha implantado de tal forma que ahora ésta ya no puede desligarse de ningún proceso. En este sentido, la bibliotecología y la documentación como actividades profesionales, se verían también implicadas. Así, Castell propone: "Información y conocimiento son las variables decisivas en la productividad y en la competitividad. No quiero decir que el capital 
Hacia el establecimiento del perfil del bibliotecólogo a nivel ...

no cuente. Sí que es importante. Pero con conocimiento y tecnología y sin capital, se puede llegar a generar bastante capital, y sino que se lo pregunten a Bill Gates. En cambio, con capital, pero sin tecnología y conocimiento se pierde ese capital, y sino que se lo pregunten a RCA, por ejemplo, que fue a la quiebra porque no desarrolló la tecnología adecuada en su momento" (Castell, 1999). Por su parte, Alvin Toffler (1999), antes de que se iniciara el siglo actual, ya avanzaba, como es habitual en él, algunas de las cuestiones fundamentales que sucederían en el ámbito de la educación en una entrevista realizada en Los Ángeles por Jorge Nascimento Rodrigues, Toffler señalaba: "Las dos condiciones básicas para una estrategia basada en el conocimiento son una inversión masiva en nuevas formas de enseñar de cara a una población más educada y una infraestructura electrónica y comunicacional. Es éste el desafío que las Naciones y los grandes bloques tendrán en el próximo siglo”. Por este motivo, la simple razón de "discutir" sobre un plan de formación para los bibliotecólogos y los documentalistas ya es una idea suficiente para hacer de estos estudios un ejemplo de actualidad y preparación para los bibliotecarios del siglo XXI. No hay recetas ni fórmulas mágicas. Hay, eso sí, más recursos y éstos son más accesibles, pero si detrás no está un formador bien preparado, con suficiente conocimiento y 
Conocimiento tecnológico para el desarrollo de la actividad ...

con un plan integral educativo que incluya lo que se hace en diferentes escuelas o facultades, el resultado no será favorable. Y la última razón subyacente en esto, la justificación que tienen los docentes es la mejoría de la sociedad a través del conocimiento. Ésa es la mejor forma de devolver con creces la confianza que la sociedad pide cuando facilita los recursos financieros para dar una educación de calidad. No se trata de separar, sino de aunar esfuerzos políticos y económicos para hacer que los estudios de bibliotecología y documentación tengan una perspectiva profesional digna.

Otro autor que le abrió las puertas a la llamada Sociedad de la Información o Sociedad del Conocimiento es John Naisbitt. En apenas una década, algunas de sus previsiones se están cumpliendo tal y como él las predijo. Aquellos que lo tacharon de futurólogo y oportunista ahora no se sabe bien dónde están. Decía Naisbitt que: "La nueva fuente del poder ya no es el dinero en manos de pocos, sino la información en manos de muchos".

Ése es el riesgo que corren las sociedades a la hora de educar. Es tanta la información que se posee que apenas se acierta a utilizar de forma consecuente. Frente a etapas de la historia muy limitadas por el control de los contenidos, en la actualidad existe una excelente oferta informativa que ayuda a los docentes en la preparación de sus clases y a los 
Hacia el establecimiento del perfil del bibliotecólogo a nivel ...

alumnos a tener una visión más global de los estudios en los que están implicados.

El libro que mejor resume las aportaciones de John Naisbitt (1994) es Global Paradox y debería ser cabecera de la mayoría de las facultades que creen que la tecnología y la información forman parte de la actividad académica y científica del siglo XXI. En este libro el autor reflexiona sobre el impacto que han producido las nuevas tecnologías de comunicación en la economía mundial. El resto de autores aquí citados han trabajado sobre una línea de trabajo que relaciona la economía con la educación y, en medio de ambas, como motor que impulsa la sociedad, se encuentra, por supuesto, la información.

\section{La tecnología al servicio de los profesiona- les en bibliotecología y documentación}

Las ideas plasmadas con anterioridad han sido asumidas en muchas de las disciplinas universitarias. El pensamiento de Toffler, Castell o Naisbitt son un ejemplo para entender la sociedad actual en relación con la información. El elemento fundamental del conocimiento es precisamente la información. El motor de la economía mundial fue durante años el carbón, que cedió su trono al petróleo y éste, en proceso de desaparición, ha entregado su testigo a la información. En efecto, el mundo se concibe en 
Conocimiento tecnológico para el desarrollo de la actividad ...

función del intercambio de información. Para la toma de decisiones es preciso que cualquier profesional esté bien formado y mejor informado. Esta regla de oro debería figurar en todos los manuales de recursos humanos.

Sin ánimo de polemizar ni de hacer predicciones que seguramente no se cumplirán, el uso de la tecnología entre los profesionales de la bibliotecología y la documentación sigue siendo escaso. ¿Dónde radica el problema? Quizás en la formación que reciben. Si otras disciplinas han dado un giro radical en su formación ¿por qué no lo ha hecho la bibliotecología? En este sentido los resultados del consumo tecnológico por parte de los docentes, en una investigación que realicé en 2004 para el Centro Universitario de Investigaciones Bibliotecológicas, revelaron que era muy escaso el uso de algunas herramientas que ya en otras disciplinas se estaban empleando, como el uso de los sitios e Internet, los foros, los chats o el correo electrónico con los alumnos. Es cierto, que desde entonces una gran parte de los docentes han creado sus espacios en Internet y desde allí emplean casi todos los recursos de la tecnología. Pero ¿es esto suficiente?

Si el ámbito educativo mejora, en apenas unos años habrá de verse ese resultado, incluso mayor, en las bibliotecas. Es preciso señalar que muchos bibliotecarios ya usaban la tecnología en algunas de 
Hacia el establecimiento del perfil del bibliotecólogo a nivel ...

sus actividades cotidianas, como la catalogación en línea o la consulta online a bases de datos. Así, el camino iniciado recientemente servirá para que los bibliotecarios amplíen su formación tecnológica y la pongan al servicio de los usuarios.

Los estudios en bibliotecología están adaptándose constantemente a la nueva realidad gracias al trabajo y esfuerzo de varios colectivos. Algunos de ellos serían el actual Seminario del CUIB, que tiene como punto de discusión: "Los problemas y fenómenos que tienen relación directa con la educación bibliotecológica y su entorno social en Latinoamérica", donde se repasan las diferentes tareas y actividades académicas a través de un Foro en el que participan docentes de diversos países que imparten docencia en esta área; y en las reuniones que se hacen sobre Formación de Recursos Humanos para las Bibliotecas. Precisamente, en la VII Mesa Redonda, celebrada en México D. F., en el 2001 se recogieron las líneas maestras en las que habrá de avanzarse en los estudios de bibliotecología en relación con las tecnologías de la información:

1. Analizar la factibilidad de automatizar cada una de las áreas de las bibliotecas.

2. Evaluar el equipo de cómputo que se necesita para automatizar servicios y bibliotecas

3. Evaluar software para la automatización de bibliotecas 
Conocimiento tecnológico para el desarrollo de la actividad ...

4. Planear la automatización de las bibliotecas.

5. Proporcionar los elementos que permitan el diseño de las bases de datos necesarias para el funcionamiento óptimo de la biblioteca

Pero la tecnología en las bibliotecas es algo más que todo eso. Estas cinco ideas son tan sólo una parte del enfoque total que la biblioteca debe afrontar en la actualidad.

Hay dos razonamientos inseparables del resto: las herramientas de gestión bibliotecaria y la implementación de la tecnología de uso común en las bibliotecas. Tras más de cuatro décadas de que algunas bibliotecas estuvieran usando algunas bases de datos, la llegada de Internet abrió el mundo de la información de tal forma que las bibliotecas perdieron la oportunidad más grande que tuvieron para usar las bases de datos de modo que los usuarios dispusieran de recursos en abundancia y los consiguieran de forma rápida y precisa. Visto desde otro perfil, gracias a los fondos depositados y gestionados en las bibliotecas, Internet está ofreciendo miles de documentos que antes apenas eran visibles y muy poca gente consultaba.

Así pues, los bibliotecarios disponen cada vez de más y mejores herramientas para su gestión. Las bases de datos se amplían y se modernizan para hacerse cada vez más fáciles para el usuario. Los profesionales de las bibliotecas están adaptando buena parte 
Hacia el establecimiento del perfil del bibliotecólogo a nivel ...

de sus fondos para dirigirlos hacia Internet, donde saben que encontrarán millones de usuarios que antes no tenían. Ésa es, quizás, la razón más importante para que los bibliotecarios accedan a la tecnología. Emplear sus recursos para ofrecerles a más usuarios los fondos que antes sólo se consultaban de forma presencial. Sin las nuevas tecnologías, las bibliotecas seguirán siendo el referente exclusivo para conseguir información. Con ellas, son el complemento ideal para que los usuarios accedan a millones de documentos, tanto en línea, como de forma presencial.

\section{A modo de conclusiones}

Los avances en las bibliotecas actuales son fruto de una educación bibliotecológica alimentada en las ciencias humanas, pero también en el desarrollo de una tecnología que permite obtener excelentes bibliotecarios, conocedores de la realidad humana y social de sus usuarios y al mismo tiempo detentadores de buenas dotes de gestión, análisis y planificación de las tareas bibliotecarias, gracias a los recursos y programas informativos de uso común en estas tareas.

Es un hecho constatado que las bibliotecas han creído siempre en la tecnología, y que el primer paso se dio hace más de tres mil años cuando se ordenaron y clasificaron los documentos en la anti- 
Conocimiento tecnológico para el desarrollo de la actividad ...

gua Mesopotamia. Y desde entonces el camino recorrido es paralelo en la forma pero no en el fondo, la mayor parte de las veces debido a problemas de financiación. Sin embargo los bibliotecarios fueron ideando sistemas de clasificación que ordenaron los miles y millones de documentos que ya encerraban algunas bibliotecas. El cambio radical en las tecnologías, sobre todo debido a la revolución informática, obligó a los bibliotecarios a crear bases de datos que facilitaban una mayor y mejor consulta de sus fondos por parte de los usuarios.

Los pensadores actuales citados en este artículo son una muestra de lo que las bibliotecas pueden aportarle a la sociedad a través del conocimiento, cuya materia prima fundamental es la información. Estos autores plantean una sociedad más dinámica, un intercambio más fluido de información y una mayor rapidez para que los usuarios puedan tener más posibilidades en su trabajo.

La formación bibliotecológica requiere un esfuerzo por parte de los docentes para preparar un perfil que se adapte a las nuevas demandas de la sociedad, perfil que es necesariamente cambiante dado que la rapidez con la que se suceden los cambios es cada día mayor. La universidad es responsable del éxito o fracaso de los bibliotecarios. Por fortuna cada vez hay un mayor interés en el estudio y 
Hacia el establecimiento del perfil del bibliotecólogo a nivel ...

tratamiento de los perfiles que conformarán a los nuevos bibliotecarios.

Queda un esfuerzo complementario que también debe hacer la educación bibliotecológica: la lectura. Conseguidas altas cotas lectoras en todo el mundo y con un bajo porcentaje de analfabetismo, la batalla se centra ahora en una lectura reflexionada, reposada y amena para los lectores. Debemos conseguir, a base de esfuerzo, que los lectores continúen considerando a la biblioteca como el templo del saber, el lugar donde una lectura llena el espíritu de quien lee, y el sitio donde la información sigue fluyendo de libros, revistas, bases de datos y lugares de Internet en los que se puede tener confianza y garantía informativas.

Aunque esto pueda sonar muy crítico, el éxito de las bibliotecas viene necesariamente precedido de una buena formación docente entre sus trabajadores. En tiempos en los que la información fluye de manera dinámica, el papel del bibliotecario debe ser similar al de un faro que guía a los barcos en un mar oscuro y lleno de nubes. En la actualidad la información contenida en libros y revistas se ha incrementado exponencialmente hasta niveles insospechados. En ese "océano de datos" no tardarán mucho los lectores, en volver a las bibliotecas a pedir el sabio consejo de los bibliotecarios. Entonces vendrá la gran prueba de fuego que develará si el bi- 
Conocimiento tecnológico para el desarrollo de la actividad ...

bliotecario es algo más que un suministrador de datos y vuelva a su antigua misión de orientar, ayudar, enseñar, colaborar, participar, recopilar, mostrar y ayudar al usuario a resolver sus necesidades lectoras, educativas, investigadoras y/o profesionales. Ése es el gran reto del bibliotecario del siglo XXI: mantener el espíritu abierto para que los jóvenes lectores que visitan la biblioteca se encuentren en un lugar del cual mana la sabiduría.

\section{Bibliografía}

Agencias Informativas: "Proponen rediseñar sistema educativo", en Notimex, 28-2-2007. http://srv2.vanguardia.com.mx Consultado:3-3- 2007.

Burke; James; Ornstein, Robert (2001), Del hacha al Chip. Cómo las tecnologías cambian nuestra mente, Barcelona, Planeta.

Castell, Manuel (1999), "Globalización, tecnología, trabajo, empleo y empresa”, en La Factoría, N 7 (Octubre-enero), pp. 13-38.

http://www.lafactoriaweb.com/articulos/castells7. htm Consultado: 12-4-2007.

Lozano, Inés (2002), “Analfabetismo digital, fenómeno latinoamericano", en, http://www.latecla.cu/bd/dentro/05analfabetismo ines.htm Consultado: 1-3-2007. 
Hacia el establecimiento del perfil del bibliotecólogo a nivel ...

Lyman P; Varian, HR (2003), "How much information 2003", en, http://www2.sims.berkeley.edu/research/projects/ how-much-info-2003 Consultado: 28-2-2007.

Marcin, Mauricio (2007), "Historias y revistas, no libros, lecturas favoritas del mexicano", en, http://www.cronica.com.mx/nota.php?id_nota = 160267 Consultado: 1-3-2007.

Nascimento Rodrigues, Jorge, Alvin Tofller dice que Europa sigue viviendo en el pasado. En: http://www.mujeresdeempresa.com/actualidad/ actualidad010401.shtml Consultado: 12-4-2007.

Naisbitt, John (1994) Global Paradox, New York, William Morrow \& Company, Inc.

Peña, Adriana, "Hábitos de los usuarios de Internet en México 2006", en, http://www.amipci.org.mx Consultado: 1-3-2007

Programa Nacional de Lectura, en, Secretaría de Educación Pública, http://www.sep.gob.mx/wb2/sep/Programa Nacional_de_Lectura consultado: 3-3-2007. 


\title{
El perfil del graduado en bibliotecología
}

\author{
Alice Miranda ARguedas
}

$\mathbf{P}$

areciera, por lo expuesto en los diferentes documentos de base y en la discusión, que todos los trabajos apuntan hacia un perfil profesional que dé respuestas a la Sociedad de la Información-Conocimiento o de Aprendizaje y a un mundo académico global. Hay tanto a lo que hay que darle respuesta y tomar en consideración al diseñar un plan de estudio para que cumpla con los propósitos para los cuales se crea, que el intento se convierte en sólo unas pinceladas del mundo que se desea abarcar. El perfil del graduado es uno de los apartados a los que mayor atención se le presta y éste muy pocas veces satisface completamente lo que en él se anota. Siempre pensamos que faltó algo muy importante que responda al cuestionamiento de si somos o no eficientes e indispensables. De las muchas lecturas obligatorias para sustentar el perfil del graduado deseado recomiendo prestar atención a las normas relacionadas con las competencias para la Alfabetización Informacional 
Hacia el establecimiento del perfil del bibliotecólogo a nivel ...

(ALFIN), entre las cuales se destacan las siguientes: ACRL's Information Literacy Competency Standards of Higher Education (Association of College and Research Libraries 2000); CUAL's Australian and New Zealand Information Literacy Framework: principles, standards and practice (Versión revisada de CUAL's Information Literacy Standards publicadas en 2001), y SCONUL's The Seven Pillars of Information Literacy (SCONUL Information Skills Task Force 1999), que determinan las competencias de las personas para acceder y usar la información; helas aquí:

\begin{tabular}{|l|l|l||}
\hline $\begin{array}{c}\text { ACRL's Information Lite- } \\
\text { racy Competency Stan- } \\
\text { dards of Higher } \\
\text { Education }\end{array}$ & $\begin{array}{c}\text { CUAL's Australian and } \\
\text { New Zealand Informa- } \\
\text { tion Literacy } \\
\text { Framework }\end{array}$ & $\begin{array}{c}\text { SCONUL's The Seven } \\
\text { Pillars of Information } \\
\text { Literacy }\end{array}$ \\
\hline $\begin{array}{l}\text { Determinar el alcance de la } \\
\text { información requerida. }\end{array}$ & $\begin{array}{l}\text { Reconocer la necesidad } \\
\text { de información y determi- } \\
\text { nar la naturaleza y nivel } \\
\text { de la información que se } \\
\text { necesita. }\end{array}$ & $\begin{array}{l}\text { Reconocer la necesidad } \\
\text { de conseguir información. }\end{array}$ \\
\hline $\begin{array}{l}\text { Acceder a ella con eficacia y y } \\
\text { eficiencia. }\end{array}$ & $\begin{array}{l}\text { Encontrar la información } \\
\text { que se necesita de ma- } \\
\text { nera eficaz y eficiente. }\end{array}$ & $\begin{array}{l}\text { Distinguir entre distintas } \\
\text { formas de cubrir la nece- } \\
\text { sidad. }\end{array}$ \\
\hline $\begin{array}{l}\text { Evaluar de forma crítica la } \\
\text { información y sus fuentes. }\end{array}$ & $\begin{array}{l}\text { Evaluar críticamente la } \\
\text { información y el proceso } \\
\text { de búsqueda de la infor- } \\
\text { mación. }\end{array}$ & $\begin{array}{l}\text { Establecer estrategias } \\
\text { para localizar informa- } \\
\text { ción. }\end{array}$ \\
\hline $\begin{array}{l}\text { Incorporar la información se- } \\
\text { leccionada a su propia base } \\
\text { de conocimientos. }\end{array}$ & $\begin{array}{l}\text { Gestionar la información } \\
\text { reunida o generada. }\end{array}$ & $\begin{array}{l}\text { Localizar la información y } \\
\text { acceder a ella. }\end{array}$ \\
\hline \hline
\end{tabular}


El perfil del graduado en bibliotecología

\begin{tabular}{||l|l|l||}
\hline $\begin{array}{c}\text { ACRL's Information Lite- } \\
\text { racy Competency Stan- } \\
\text { dards of Higher } \\
\text { Education }\end{array}$ & $\begin{array}{c}\text { CUAL's Australian and } \\
\text { New Zealand Informa- } \\
\text { tion Literacy } \\
\text { Framework }\end{array}$ & $\begin{array}{c}\text { SCONUL's The Seven } \\
\text { Pillars of Information } \\
\text { Literacy }\end{array}$ \\
\hline $\begin{array}{l}\text { Utilizar la información de } \\
\text { manera eficaz para acome- } \\
\text { ter tareas específicas. }\end{array}$ & $\begin{array}{l}\text { Aplicar la información an- } \\
\text { terior y la nueva para } \\
\text { construir nuevos concep- } \\
\text { tos o crear nuevas for- } \\
\text { mas de comprensión. }\end{array}$ & $\begin{array}{l}\text { Comprar y evaluar la in- } \\
\text { formación. }\end{array}$ \\
\hline $\begin{array}{l}\text { Comprender la problemática } \\
\text { económica legal y social } \\
\text { que rodea el uso de la infor- } \\
\text { mación y acceder a ella y } \\
\text { utilizarla de forma ética y } \\
\text { legal. }\end{array}$ & $\begin{array}{l}\text { Utilizar la información } \\
\text { con sensatez y mostrar } \\
\text { sensibilidad a las cues- } \\
\text { tiones culturales, éticas, } \\
\text { económicas, legales y } \\
\text { sociales que rodean el } \\
\text { uso de la información. }\end{array}$ & $\begin{array}{l}\text { Organizar, aplicar y co- } \\
\text { municar la información. }\end{array}$ \\
\hline & \multicolumn{2}{|l||}{} \\
\hline
\end{tabular}

Estas competencias se relacionan con las destrezas que todo ser humano debe tener la oportunidad para adquirir: el uso de las tecnologías de información y la comunicación (TIC), incorporadas al sistema educativo y la sociedad para que se vuelvan un aprendizaje continuo a lo largo de la vida, pero que el graduado en Bibliotecología e Información debe liderar. Además, un graduado en Bibliotecología y Documentación debe aportarle a la Sociedad de la Información-Conocimiento o del Aprendizaje sus capacidades para planificar, organizar y diseminar los servicios informacionales de la institución a la 
que sirve, ofreciendo los servicios con eficacia y eficiencia. Cita Valentim (2004, p. 4) que las competencias y habilidades recibídas a través de la formación profesional en el área de Ciencias de la Información, más específicamente en Bibliotecología y Documentación deben ser:

\begin{tabular}{|c|c|c|c|}
\hline $\begin{array}{l}\text { Competencias de } \\
\text { comunicación y } \\
\text { expresión }\end{array}$ & $\begin{array}{l}\text { Competencias } \\
\text { técnico científicas }\end{array}$ & $\begin{array}{l}\text { Competencias } \\
\text { gerenciales }\end{array}$ & $\begin{array}{c}\text { Competencias sociales } \\
\text { y políticas }\end{array}$ \\
\hline \begin{tabular}{||l} 
Formular y geren- \\
ciar proyectos de \\
información. Apli- \\
car técnicas de \\
mercadotecnia, de \\
liderazgo y de rela- \\
ciones públicas. \\
Capacitar y orien- \\
tar a los usuarios \\
para hacer un me- \\
jor uso de los re- \\
cursos de informa- \\
ción disponibles en \\
las unidades de in- \\
formación docu- \\
mental. Elaborar \\
productos de infor- \\
mación (bibliogra- \\
fías, catálogos, \\
guías, índices, di- \\
seminación selecti- \\
va de la informa- \\
ción (DSI), etc..;
\end{tabular} & $\begin{array}{l}\text { Desarrollar y ejecutar } \\
\text { el procesamiento de } \\
\text { documentos en distin- } \\
\text { tos soportes en unida- } \\
\text { des, sistemas y servi- } \\
\text { cios de información. } \\
\text { Seleccionar, registrar, } \\
\text { almacenar, recuperar y } \\
\text { difundir la información } \\
\text { grabada en cualquier } \\
\text { medio para los usua- } \\
\text { rios de unidades, ser- } \\
\text { vicios y sistemas de in- } \\
\text { formación documental. } \\
\text { Elaborar productos de } \\
\text { información (bibliogra- } \\
\text { fías, catálogos, guías, } \\
\text { índices, diseminación } \\
\text { selectiva de la informa- } \\
\text { ción (DSI), etcétera). } \\
\text { Utilizar y divulgar fuen- } \\
\text { tes, productos y recur- } \\
\text { sos de información en } \\
\text { diferentes soportes. }\end{array}$ & $\begin{array}{l}\text { Dirigir, administrar, organizar y } \\
\text { coordinar unidades, sistemas y } \\
\text { servicios de información. For- } \\
\text { mular y gerenciar proyectos de } \\
\text { información. Aplicar técnicas de } \\
\text { mercadeo, de liderazgo y de re- } \\
\text { laciones públicas. Buscar, re- } \\
\text { gistrar, evaluar y difundir la in- } \\
\text { formación con fines } \\
\text { académicos y profesionales. } \\
\text { Elaborar productos de informa- } \\
\text { ción (bibliografías, catálogos, } \\
\text { guías, índices, diseminación se- } \\
\text { lectiva de la información (DSI), } \\
\text { etc.). Asesorar en el planea- } \\
\text { miento de recursos económico } \\
\text { financieros y humanos del sec- } \\
\text { tor. Planear, coordinar y evaluar } \\
\text { la preservación y conservación } \\
\text { de acervos documentales. Pla- } \\
\text { near y ejecutar estudios de } \\
\text { usuarios y formación de usua- } \\
\text { rios de la información. Planear, } \\
\text { constituir y manipular redes glo- } \\
\text { bales de información. }\end{array}$ & $\begin{array}{l}\text { Seleccionar y evaluar todo } \\
\text { tipo de material para las } \\
\text { unidades de información } \\
\text { documental. Buscar, re- } \\
\text { gistrar, evaluar y difundir } \\
\text { la información con fines } \\
\text { académicos y profesiona- } \\
\text { les. Asesorar e intervenir } \\
\text { en la formulación de políti- } \\
\text { cas de información docu- } \\
\text { mental. Asesorar en el } \\
\text { planeamiento de recursos } \\
\text { económico financieros y } \\
\text { humanos del sector. Pla- } \\
\text { near y ejecutar estudios } \\
\text { de usuarios y formación } \\
\text { de usuarios de la informa- } \\
\text { ción. Promover una acti- } \\
\text { tud crítica y creativa con } \\
\text { respeto a las resoluciones } \\
\text { de problemas y cuestio- } \\
\text { nes de información. }\end{array}$ \\
\hline
\end{tabular}




\section{El perfil del graduado en bibliotecología}

\begin{tabular}{|c|c|c|c|}
\hline $\begin{array}{l}\text { Competencias de co- } \\
\text { municación y } \\
\text { expresión }\end{array}$ & $\begin{array}{l}\text { Competencias } \\
\text { técnico científicas }\end{array}$ & $\begin{array}{l}\text { Competencias } \\
\text { gerenciales }\end{array}$ & $\begin{array}{c}\text { Competencias sociales } \\
\text { y políticas }\end{array}$ \\
\hline $\begin{array}{l}\text { Ejecutar procedimientos } \\
\text { automatizados propios } \\
\text { en un entorno informati- } \\
\text { zado. Planear y ejecutar } \\
\text { estudios de usuarios y } \\
\text { de formación de usua- } \\
\text { rios de la información. }\end{array}$ & $\begin{array}{l}\text { Reunir y valorar documentos y } \\
\text { archivar, preservar y conservar } \\
\text { los materiales almacenados en } \\
\text { las unidades de información do- } \\
\text { cumental. Seleccionar y evaluar } \\
\text { todo tipo de material para las uni- } \\
\text { dades de información. Buscar, } \\
\text { registrar, evaluar y difundir la in- } \\
\text { formación con fines académicos } \\
\text { y profesionales. Ejecutar procedi- } \\
\text { mientos automatizados propios } \\
\text { en un entorno informatizado. Pla- } \\
\text { near, constituir y manipular redes } \\
\text { globales de información. Formu- } \\
\text { lar políticas de investigación en } \\
\text { Bibliotecología y Ciencia de la } \\
\text { Información. Realizar investiga- } \\
\text { ción y estudios sobre desenvolvi- } \\
\text { miento y aplicación de metodolo- } \\
\text { gías de elaboración y utilización } \\
\text { del conocimiento registrado. Ase- } \\
\text { sorar e intervenir en la elabora- } \\
\text { ción de normas jurídicas en Bi- } \\
\text { bliotecología y Ciencia de la } \\
\text { Información. Asesorar la evalua- } \\
\text { ción de colecciones bibliográfico } \\
\text { documentales. Realizar pericias } \\
\text { referentes a la autenticidad, anti- } \\
\text { güedad, procedencia y estado } \\
\text { general de materiales impresos } \\
\text { de valor bibliográfico. }\end{array}$ & & $\begin{array}{l}\text { Fomentar una actitud } \\
\text { abierta e interactiva con } \\
\text { los diversos actores socia- } \\
\text { les (políticos, empresa- } \\
\text { rios, educadores, trabaja- } \\
\text { dores y profesionales de } \\
\text { otras áreas, instituciones y } \\
\text { ciudadanos en general). } \\
\text { Identificar las nuevas de- } \\
\text { mandas sociales de infor- } \\
\text { mación. Contribuir para } \\
\text { definir, consolidar y desa- } \\
\text { rrollar el mercado de tra- } \\
\text { bajo del área. Actuar co- } \\
\text { lectivamente con sus } \\
\text { colegas en el ámbito de } \\
\text { las instituciones sociales, } \\
\text { con el objetivo de promo- } \\
\text { ver y defender la profe- } \\
\text { sión. Formular políticas de } \\
\text { investigación en Bibliote- } \\
\text { cología y Ciencia de la } \\
\text { Información. Asesorar e } \\
\text { intervenir en la elabora- } \\
\text { ción de normas jurídicas } \\
\text { en Bibliotecología y Cien- } \\
\text { cia de la información. }\end{array}$ \\
\hline
\end{tabular}


Hacia el establecimiento del perfil del bibliotecólogo a nivel ...

Además de estas competencias, como han anotado de alguna manera ustedes, un profesional requiere también las actitudes de respeto/tolerancia, innovación/creatividad, sensibilidad hacia el comportamiento de la comunidad a la que sirve, ética profesional, compromiso social, responsabilidad y trabajo en equipo, para lograr posicionarse en el mundo laboral moderno. Valentin, M. (2004) [Competencias y habilidades del profesional en el área de Bibliotecología y Documentación ], [Brasil :s.n.] 2007-04-25. 


\section{Discusión}

T a discusión en el Foro Electrónico sobre el tema tecólogo a nivel Iberoamérica" partió del cambio acelerado que se ha dado en nuestra sociedad, apoyado por el desarrollo de las tecnologías y las telecomunicaciones y que nos ha acercado a la Sociedad del Conocimiento. Esto nos llevó a reflexionar sobre el perfil del profesional de la bibliotecología como un conjunto de conocimientos, habilidades y aptitudes que debe incorporar el estudiante para darle respuestas a esta sociedad.

También partimos de otras consideraciones que, de acuerdo con los participantes, deberíamos tomar en cuenta, como son: la brecha económica y tecnológica de los diferentes países de la región; las diferencias entre conectividad, equipamiento tecnológico y desigualdad social, que además requieren de una mente abierta para dar lugar a la creatividad; los aspectos multi y pluriculturales de los diversos países y aun al interior de cada uno, así como los diversos entornos educativos de cada país. 
Hacia el establecimiento del perfil del bibliotecólogo a nivel ...

Considerando todos los aspectos anteriores, antes de hablar de un perfil bibliotecológico para la región, se insistió en la necesidad de elaborar un diagnóstico objetivo del presente y un pronóstico de mediano plazo que nos indicaran cómo ha de transformarse la sociedad. De este modo podríamos quizá esperar constituir un vínculo bidireccional y pertinente entre la sociedad y la educación bibliotecológica. En esta vinculación sería necesario tomar en cuenta el peso que tiene la dimensión social a través de algunas de sus manifestaciones: sociedad y tecnología; sociedad y mercado de trabajo; sociedad nacional e internacional, así como sociedad y educación superior, sólo por nombrar algunos aspectos del amplio panorama implícito y explícito que plantean las reformas curriculares y que nos llevarán a reformular el tipo de profesional que queremos formar.

Otro punto importante a considerar es el equilibrio entre la teoría y la experiencia profesional, requerida como elemento de formación; pensando que la formación del profesional en bibliotecología debe ser integral y que además de los conocimientos teóricos y prácticos que median en todo plan de estudios se deben apuntar algunas características de actitud y que deben ser parte del profesional: comunicación personal, deseos de superación y actitud positiva al cambio, empatía con los usuarios, 
trabajo en equipo, compromiso con la excelencia, competitividad, interés por el área de conocimiento del lugar donde labora y ética profesional. Estas actitudes unidas a la formación recibida en su centro de estudios le permitirán al profesional desenvolverse y prestar servicios de calidad, además de mantener el compromiso con su profesión y con la sociedad a la que sirve.

Por otro lado, también es necesario considerar que no se deben atender exclusivamente las necesidades del mercado laboral sino desarrollar competencias ideológicas para responder, además, a las necesidades sociales de la región latinoamericana dentro del contexto de globalización. Nuestra profesión cumple una función social perfectamente delimitada y necesaria en la que es vital contar con una perspectiva sólida sobre lo que es el mundo y cuáles son las consecuencias del trabajo bibliotecológico y los valores culturales refrendados a través del ejercicio profesional.

Así, los planes de estudio obedecen en primera instancia a las necesidades de la sociedad, aunque la oferta académica también debe ajustarse a una serie de ejes transversales e institucionales. Todo plan de estudios debe tomar en consideración las siguientes áreas disciplinarias: organización de la información documental; investigación; lectores/usuarios/clientes de la información; administración de recursos y 
Hacia el establecimiento del perfil del bibliotecólogo a nivel ...

servicios de información, y otros ejes curriculares como la gestión de unidades de información documental; las tecnologías de la información y la comunicación, y los métodos y técnicas de investigación y alfabetización informacional. Ahora bien, si este núcleo básico le da sentido a la formación, podemos justificar que al abrir ésta a las nuevas tecnologías se tiende a agilizar procesos y a mejorar servicios; es decir, debemos considerar a la tecnología y al diseño de procesos de gestión informativa mediante las nuevas tecnologías de la información sólo como un medio, no como un fin del perfil profesional del bibliotecólogo.

\section{Conjunto de conocimientos o ¿núcleo básico?}

Respecto de estas nuevas interrogantes los participantes comentaron que debe existir un núcleo básico de conocimientos que esté presente en los currículos que forman a los bibliotecólogos de la región, lo que deberá ser complementado con las características propias de la localidad para que los profesionales sean capaces de satisfacer las demandas propias de su entorno. Es difícil estructurar un currículo único, como lo señala Pirela citando a Chiñas (ejemplifica el caso de México); sin embargo, considero que esto no es una cuestión de conocimientos sino de políticas institucionales. Lo que de- 
bemos de tener bien claro es que la esencia de la Bibliotecología no son las tecnologías, sino aquellos elementos teóricos que sustentan la disciplina. La formación que debe tener un bibliotecólogo tiene que orientarse hacia la solución de los problemas informacionales que la sociedad le demanda, independientemente de la tipología de los soportes. Las tecnologías son solamente el medio para agilizar los servicios y procesos que se llevan a cabo en la unidad de información donde se desenvuelve el bibliotecólogo, no el fin del perfil profesional de ésto.

Otra propuesta sobre núcleos básicos la da el Colegio Nacional de Bibliotecarios, el que manifiesta las siguientes áreas de conocimiento básico: a) Organización bibliográfica y documental, b) Recursos de información documental, c) Administración de las unidades y sistemas de información, d) Servicios bibliotecarios y de información, e) Tecnología de la información, f) Metodología y g) Básica; en la que pueden insertarse las vertientes mencionadas en diversos estudios: 1). Conocimientos profundos, 2). Conciencia social, 3). Aprender a aprender para adaptase a nuevas situaciones y 4). Conocimientos prácticos, como lo menciona Tarango.

A pesar de la diversidad de opiniones sobre la enorme dificultad que representa el hecho de querer hacer un perfil bibliotecológico internacional y de la falta de otra discusión a fondo sobre el tema, 
Hacia el establecimiento del perfil del bibliotecólogo a nivel ...

en el Foro se mencionaron una serie de conocimientos, habilidades y aptitudes generales que se exponen a continuación:

\section{Conocimientos necesarios}

- Los principios básicos de la bibliotecología así como sus tendencias en el ámbito internacional y nacional, que apoyen la formación de profesionales críticos, que tomen como base la teoría para analizar, razonar y comprender su profesión, su disciplina y su entorno para darle solución a los problemas que su profesión y la sociedad le impongan.

- Los conocimientos de práctica profesional que le permitan al profesional resolver problemas concretos y ofrecer soluciones sencillas para contribuir al desarrollo social.

- Su historia: la evolución, tipología y función social de las diferentes clases de documentos existentes en las bibliotecas y otras unidades involucradas en el flujo de la información documental.

- Las teorías y principios relacionados con los marcos tradicionales y emergentes de la producción, organización y difusión de la información documental.

- Los métodos, técnicas y medios apropiados para planear, organizar y administrar servicios bibliotecarios y de información. 
Discusión

- Los métodos y técnicas aplicables al estudio de las necesidades de información de las diferentes comunidades.

- La gestión y organización, la formación de usuarios, la educación e investigación, la administración de recursos y los servicios de información.

- La tecnología que puede ser aplicada en las actividades profesionales y disciplinarias. La tecnología es un medio y las áreas que nos identifican como bibliotecólogos siguen siendo las mismas; es decir seguimos aprendiendo a organizar y administrar información, pero también hay que considerar que la tecnología le permite al bibliotecario agilizar sus actividades, modificarlas y hasta planearlas; sin embargo, es necesario tomar en cuenta que el avance tecnológico y en las telecomunicaciones han obligado a quienes diseñan planes de estudio a considerar el área tecnológica como parte importante del perfil de egreso de nuestros profesionales.

- Los fundamentos teóricos, métodos y técnicas para llevar a cabo tareas de investigación aplicada a la resolución de problemas en el ejercicio profesional.

- Mercadotecnia y técnicas de venta: tradicionalmente las cosas que se hacen en la biblioteca tienen poca repercusión. Pero ahora se presentan nuevos retos que necesitan nuevas técnicas, co- 
Hacia el establecimiento del perfil del bibliotecólogo a nivel ...

nocimientos y habilidades que permitan diseñar y proyectar una imagen pública positiva de nuestros servicios, por lo que la mercadotecnia constituye un instrumento idóneo para mejorar la comunicación entre nuestros productos y servicios, y ofrecerle al cliente la opción de conocer mejor las posibilidades informativas.

- Se dijo también que se requieren ciertos conocimientos de otras disciplinas y de otro idioma. Se propone que el perfil profesional del bibliotecólogo se sustente en la interdisciplinariedad del conocimiento.

Hoy en día debe considerase lo que dice Rodríguez: "[...] los principales cambios a los que se enfrentan los profesionales en bibliotecología y documentación, se centran en: desarrollar un alto nivel de conocimiento de las nuevas tecnologías de la información y la comunicación, facilitar el acceso y uso de la información, demostrar habilidades en la gestión, así como, responder a las demandas del mercado laboral[...] [donde] [...] el nuevo profesional deba tener competencias en aspectos de gestión y organización, conocimientos en varias disciplinas: formación de usuarios, educación, investigación, administración de recursos y servicios de información, tecnologías de la información y la comunicación. Aunado a esto debe tener una formación humanística que complemente su forma- 
Discusión

ción integral, ser innovador, creativo y proactivo, entre otros".

\section{Actitudes}

En lo que se refiere a las actitudes que deben fomentarse en los estudiantes de bibliotecología, están:

- Una actitud positiva, la cual es necesaria para enfrentar los retos que la sociedad cambiante impone; convencer, por ejemplo, a las autoridades de las instituciones acerca de la trascendencia de la bibliotecología y de su impacto; sólo se puede convencer a los demás a partir de que uno mismo lo esté.

- Una actitud abierta que le permita aceptar las nuevas tecnologías, los cambios, el entorno, nuestro papel en la "selva selvagia", según Ortega y Gasset en la Misión del bibliotecario.

- Y una actitud exploratoria para acercarse a los problemas y anticiparse a los problemas proporcionando soluciones.

\section{Aptitudes}

La aptitud para el liderazgo es una habilidad potencial que implica una gran fuerza motivadora que poco se ha contemplado como necesaria en las instituciones de bibliotecología. Por ello se puede decir que a las cualidades que debe tener el bibliotecario se pueden agregar: entusiasmo, aceptación de la 
Hacia el establecimiento del perfil del bibliotecólogo a nivel ...

diversidad, dinámica, capacidad de planeación, habilidad para relacionarse, empatía, confianza, capacidad para disfrutar, organización, inquietud por investigar, persistencia, creatividad, ética, etcétera.

De esta forma, los participantes cerraron el Foro con la perspectiva de un profesional bibliotecólogo integral poseedor de una amplia formación que incluye conocimientos, habilidades, actitudes y aptitudes para enfrentar retos y cambios, pero también teniendo plena conciencia de la complejidad que implica definir un perfil profesional regional.

\section{Conclusiones}

A lo largo de esta discusión académica, basada en los documentos sobre el profesional en bibliotecología y documentación mencionados en la introducción de esta publicación, así como el conocimiento tecnológico para el desarrollo de la actividad profesional en Bibliotecología y Documentación y el perfil del graduado en bibliotecología, los participantes pudimos observar que la realización de un perfil a nivel regional convoca diversas aristas donde surgen diferencias así como puntos de concordancia, que tendrían que ser los elementos clave para alcanzar acuerdos.

Queda claro que no se pretende intervenir en la autonomía de las instituciones educativas, que son las encargadas de elaborar y actualizar los planes de 
estudio. Sin embargo, como gremio profesional comprometido con la sociedad en general, vemos la necesidad de discutir la formación de bibliotecólogos que den respuestas reales a los requerimientos que dicha sociedad está imponiendo, teniendo pleno conocimiento de las dificultades que conlleva esta tarea.

Conjuntar los conocimientos técnicos necesarios con la reflexión crítica, filosófica y teórica que sustentan a la profesión bibliotecaria en una sociedad globalizada, conlleva un análisis de mayor profundidad en el que se discuta la diversidad de los aspectos culturales, sociales y educativos de cada país.

Sin embargo, aun señalando la existencia de puntos de coincidencia, la realización de una futura sesión para continuar discutiendo este tema es imprescindible, porque es necesario discutir cada uno de los aspectos mencionados para analizar su relevancia y pertinencia al hablar de un perfil general.

Esta discusión y el documento emanado de ella constituyen el precedente para delinear el conjunto de conocimientos, habilidades y aptitudes que podrían conformar un perfil para el bibliotecólogo en Iberoamérica, quedando el compromiso de una nueva sesión para profundizar la discusión y fortalecer o abandonar la idea de la creación de un perfil de esta naturaleza. 
Hacia el establecimiento del perfil del bibliotecólogo a nivel Iberoamérica. La edición consta de 150 ejemplares. Coordinación editorial, Zindy E. Rodríguez Tamayo. Formación editorial, Carlos Ceballos Sosa. Revisión especializada, Francisco X. González y Ortíz. Centro Universitario de Investigaciones Bibliotecológicas/UNAM. Fue impreso en papel cultural ahuesado de 90 gr. en Grupo Edición S. A. de C. V. Xochicalco 619, Col. Vértiz-Narvarte, C. P. 03600, México D. F. Se terminó de imprimir en el mes de agosto de 2008. 